\title{
A comprehensive sensitivity analysis of the WRF model for air quality applications over the Iberian Peninsula
}

\author{
Rafael Borge , Vassil Alexandrov, Juan José del Vas, Julio Lumbreras, Encarnacion Rodríguez \\ Department of Chemical and Environmental Engineering, Technical University of Madrid (UPM), c/ José Gutiérrez Abascal 2, 28006 Madrid, Spain
}

Keywords:

Air quality modelling

Meterological modelling

Sensitivity analysis

WRF setup

Iberian Peninsula

\begin{abstract}
A B S T R A C T
Meteorological inputs play a vital role on regional air quality modelling. An extensive sensitivity analysis of the Weather Research and Forecasting (WRF) model was performed, in the framework of the Integrated Assessment Modelling System for the Iberian Peninsula (SIMCA) project. Up to 23 alternative model configurations, including Planetary Boundary Layer schemes, Microphysics, Land-surface models, Radiation schemes, Sea Surface Temperature and Four-Dimensional Data Assimilation were tested in a $3 \mathrm{~km}$ spatial resolution domain. Model results for the most significant meteorological variables, were assessed through a series of common statistics. The physics options identified to produce better results (Yonsei University Planetary Boundary Layer, WRF Single-Moment 6-class microphysics, Noah Land-surface model, Eta Geophysical Fluid Dynamics Laboratory longwave radiation and MM5 shortwave radiation schemes) along with other relevant user settings (time-varying Sea Surface Temperature and combined grid-observational nudging) where included in a "best case" configuration. This setup was tested and found to produce more accurate estimation of temperature, wind and humidity fields at surface level than any other configuration for the two episodes simulated. Planetary Boundary Layer height predictions showed a reasonable agreement with estimations derived from routine atmospheric soundings. Although some seasonal and geographical differences were observed, the model showed an acceptable behaviour overall. Despite being useful to define the most appropriate setup of the WRF model for air quality modelling over the Iberian Peninsula, this study provides a general overview of WRF sensitivity and can constitute a reference for future mesoscale meteorological modelling exercises.
\end{abstract}

\section{Introduction}

Air pollution continues to be a major concern in Europe. Despite the increasing activity in the regulation of air quality and significant emission abatements during the last decades (TFIAM, 2007), further improvement on air quality levels has to be achieved for some pollutants such us ozone or particulate matter, particularly in Spain (EEA, 2007). The Integrated Assessment Modelling System for the Iberian Peninsula (SIMCA), being currently implemented by the
Technical University of Madrid, is intended to support the design and assessment of abatement strategies to comply with both future air quality standards and emission reduction commitments in Spain. The modelling system relies on the Community Multiscale Air Quality (CMAQ) model (Byun and Ching, 1999; Byun and Schere, 2006). Emissions are taken from an emission model based on the Sparse Matrix Operator Kernel Emissions (SMOKE) modelling system (UNC Carolina Environmental Program, 2005) as described in Borge et al. (2008). The meteorological model selected to provide the meteorological fields required by the chemical-transport model and the emission processing system is the Weather Research and Forecasting (WRF) modelling system (Skamarock and Klemp, 
2008). This non-hydrostatic mesoscale model constitutes a state-of-the-art atmospheric simulation system based on the Fifth-Generation Penn State/NCAR Mesoscale Model (MM5) (Grell et al., 1994).

The importance of meteorological inputs on regional air quality modelling has been clearly stated (e.g. Seaman, 2000; Pielke and Uliasz, 1998) and consequently, the need to have a better insight on the sensitivity and performance of meteorological models. Many studies have addressed comprehensive evaluations of meteorological models in the scope of air quality modelling, mainly applications of the MM5 model across the USA (Sistla et al., 2001; Mao et al., 2006; Gilliam et al., 2006), demonstrating the importance of meteorological inputs when developing air quality control strategies. These conclusions are consistent with the findings of several authors all over the world (Pirovano et al., 2007; Lee et al., 2007; Miao et al., 2007). In the context of the Iberian Peninsula, several sensitivity analyses on meteorological modelling have been carried out recently as well. Those studies were focused on particular schemes, input datasets or specific physical options implemented in MM5 in applications over limited geographical areas of Spain (Pérez et al., 2006) or Portugal (Carvalho et al., 2006). However, a comprehensive sensitivity analysis of the WRF over the whole Iberian Peninsula has not been accomplished before. Such study is needed to determine the most convenient model setup to drive air quality simulations in this geographical domain. The SIMCA project involves the simulation of multiple future-year annual scenarios developed from the Consistent Emission Projections (CEP) model (Lumbreras et al., 2008), each of them to be run under six meteorological conditions corresponding to the period 2000-2005. The computational requirements for this modelling exercise along with the need to minimize inputs uncertainties and errors make advisable to perform a comprehensive sensitivity analysis of the meteorological model selected. In this contribution, a sensitivity analysis involving the main user options available in WRF-ARW (version 2.2) regarding model physics and Four-Dimensional Data Analysis (FDDA) is presented. Up to 23 alternative configurations have been evaluated through a series of common statistics, as described in Section 2.5. From this comparison, a general model setup for the Iberian Peninsula, to be used in annual AQ simulations, is proposed and tested.

\section{Methodology}

\subsection{Modelling domains and initialization}

The modelling domains are shown in Fig. 1. The WRF model is built over a mother domain (D1) with $81 \mathrm{~km}$ spatial resolution, centred at $40^{\circ} \mathrm{N}, 3^{\circ} \mathrm{W}$. It covers the Mediterranean Sea, most of Europe and the North-Atlantic Ocean and it is intended to capture synoptic features and general circulation patterns. The first nested domain (D2), with a spatial resolution of $27 \mathrm{~km}$, comprises the Northern part of Africa and an area of the Atlantic Ocean including the Azores and Canary Islands. The innermost domain (D3) is centred over the Iberian Peninsula and consists of 468 columns and 396 rows of $3 \times 3 \mathrm{~km}^{2}$ grid cells. The three domains interact with each other through a one-way nesting strategy. The vertical structure of the model includes 30 layers covering the whole troposphere, corresponding to sigma levels of $1.000,0.999,0.997,0.9950 .992$, $0.987,0.980,0.970,0.950,0.910,0.860,0.800,0.750,0.700$, $0.650,0.600,0.550,0.500,0.450,0.400,0.350,0.300,0.250$, $0.200,0.150,0.100,0.075,0.050,0.025,0.010$ and 0.000 .

Topography, land use and land-water masks datasets were interpolated from the USGS global covers with the appropriate spatial resolution for each domain $\left(5^{\prime}, 2^{\prime}\right.$ and $30^{\prime \prime}$ for D1, D2 and D3, respectively). The USGS 25-category land use/land cover classification was considered to represent dominant vegetation types. Soil moisture and temperature are initialized from ECMWF global analysis with $1^{\circ}$ resolution.

The WRF simulations were driven by the National Centres for Environmental Prediction (NCEP) Global Tropospheric Analyses with $1^{\circ} \times 1^{\circ}$ spatial resolution and temporal resolution of $6 \mathrm{~h}$.

\subsection{Episode selection}

Simulations were conducted in two periods of the year 2005; from 19 February 00 h UTC to 28 February 00 h UTC (winter episode) and from 18 June $00 \mathrm{~h} \mathrm{UTC}$ to 27 June $00 \mathrm{~h}$ UTC (summer episode). The first two days of each period were considered as spin-up, while the remaining days are used for the analyses, i.e. $168 \mathrm{~h}$ per episode. The selection of the temporal domain to develop the sensitivity runs is based on the analysis of air pollution records across the area of interest. Generalized high concentration values of sulphur dioxide $\left(\mathrm{SO}_{2}\right)$ and particulate matter $\left(\mathrm{PM}_{10}\right.$ and $\mathrm{PM}_{2.5}$ ) were observed in Spain during the winter period, while elevated ozone $\left(\mathrm{O}_{3}\right)$ levels were registered during the summer period selected. This approach allows the evaluation of the meteorological model under different atmospheric conditions which are relevant for air quality along with a reference of the model performance under general cold and warm conditions.

Both winter (Fig. 2) and summer (Fig. 3) episodes represent a synoptic situation with weak pressure gradients, which typically results in the recirculation and accumulation of pollutants over the Iberian Peninsula (Millán et al., 1996). Particularly high temperatures characterize the summer episode with some cooler air advecting to the Iberian Peninsula from the NW at its end. In contrast with the summer period, the winter one does not exhibit relatively high temperatures. The winter episode is characterized by weak synoptic winds from NW shifting to NE at the end of the selected period.

\subsection{Scope of the sensitivity analysis}

Several physics options in WRF are available for (1) Planetary Boundary Layer, (2) microphysics, (3) Landsurface model and (4) radiation. A series of experiments changing one option at a time have been tested in this study, starting from the first option listed for each parameter in Table 1. WFR includes a number of cumulus parameterizations intended to represent vertical fluxes due to unresolved updrafts and downdrafts and compensating 


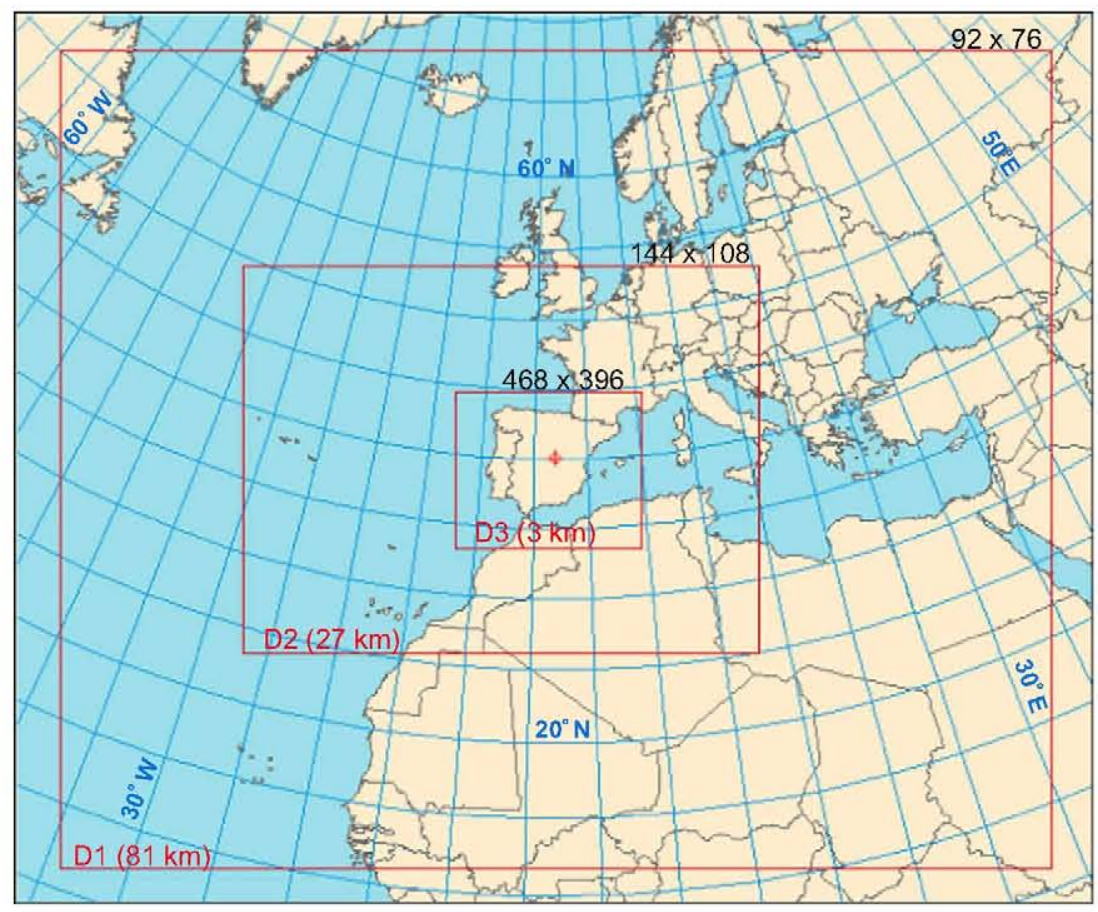

Fig. 1. WRF modelling domains (Lambert Conformal projection).

motion outside the clouds. No cumulus parameterization is needed in the innermost domain since those fluxes can be resolved explicitly at grid sizes of approximately $5-10 \mathrm{~km}$ (Skamarock et al., 2005), and therefore this issue has not been included in the study.

The impact of PBL parameterizations on air quality modelling applications has been addressed by several authors recently, Mao et al. (2006) or Pérez et al. (2006) among others. While these studies dealt with PBL schemes implemented in MM5, the three schemes available in WRF2.2 are tested in this contribution. The options to describe vertical sub-grid-scale PBL fluxes due to eddy transport in the atmosphere are the Medium Range Forecast Model (MRF) PBL scheme (Hong and Pan, 1996), the Yonsei University (YU) PBL scheme (Hong et al., 2006) and the Mellor-Yamada-Janjic (MYJ) PBL scheme (Janjic, 2002).
Friction velocities and exchange coefficients needed to estimate heat and moisture fluxes are computed through the similarity theory (MM5) surface layer scheme (described in Skamarock et al., 2005) in MRF and MYJ, while the similarity theory (Eta) surface layer scheme (Janjic, 2002) is used in the YU PBL scheme.

Clouds and precipitation play an important role on air pollution levels. Queen and Zhang (2008) demonstrated that alternative microphysics schemes in the MM5-CMAQ system could lead to significantly different predictions of PM concentrations and wet deposition. Microphysics includes explicitly resolved water vapour, cloud, and precipitation processes. Only the more sophisticated and realistic microphysics schemes, suitable for research studies (Skamarock et al., 2005) have been considered; the WRF Single-Moment 5-class (WSM5) (Hong et al., 2004)
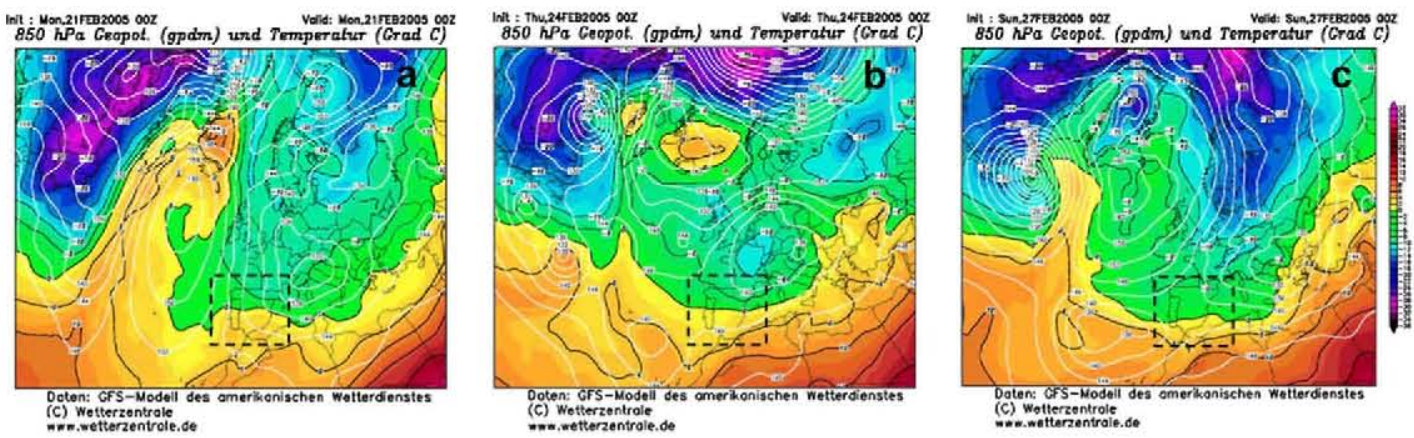

Fig. 2. Synoptic conditions during the winter episode ( $850 \mathrm{mbar}$ isobaric surface, geopotential height and temperature); 21 Feb 00 UTC (a), 24 Feb 00 UTC (b) and 27 Feb 00 UTC (c). The dashed rectangle approximately corresponds to D3. 


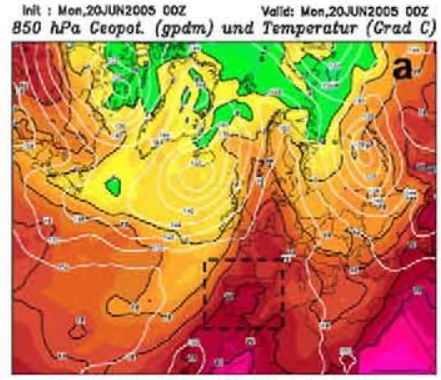

Dotanc ors-Modeli des omerivonitches wettardionstios

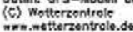

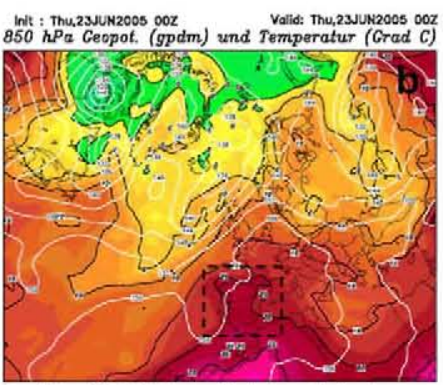

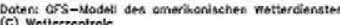
(c) Wottersontrole

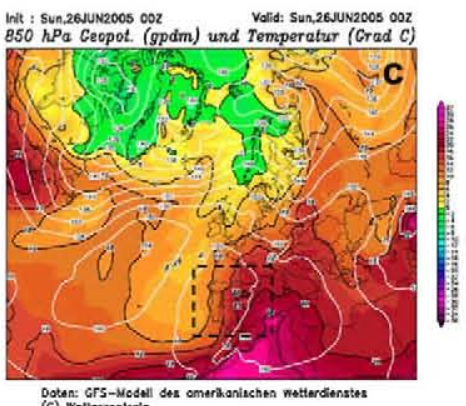

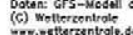

Fig. 3. Synoptic conditions during the summer episode ( 850 mbar isobaric surface, geopotential height and temperature); 20 Jun 00 UTC (a), 23 Jun 00 UTC (b) and 26 Jun 00 UTC (c). The dashed rectangle approximately corresponds to D3.

and WSM6 (Hong and Lim, 2006), the Pardue Lin scheme (Chen and Sun, 2002) and the Eta Grid-scale Cloud and Precipitation scheme (Rogers et al., 2001).

Land-surface models (LSMs) combine atmospheric information from the surface layer scheme with landsurface properties (dependent on land uses) to evaluate the vertical transport done in the PBL schemes, which has a direct influence on the estimation of the PBL height (PBLH) (Han et al., 2008). The three options currently available in WRF were tested; 5-layer thermal diffusion LSM (Dudhia, 1996), Noah LSM (Chen and Dudhia, 2001) and Rapid Update Cycle (RUC) Model (Smirnova et al., 2000).

Solar radiation is the primary driver to PBL dynamics. The radiation schemes in WRF provide atmospheric heating due to radiative flux divergence and surface downward longwave and shortwave radiation for the ground heat budget. The longwave schemes available in WRF V2.2 are the Rapid Radiative Transfer Model (RRTM) (Mlawer et al.,
1997), the Eta Geophysical Fluid Dynamics Laboratory (GFDL) scheme (Schwarzkopf and Fels, 1991) and the NCAR Community Atmospheric Model (CAM) scheme (Collins et al., 2002). The schemes included to represent shortwave processes are the Eta Geophysical Fluid Dynamics Laboratory (GFDL) scheme (Lacis and Hansen, 1974), MM5 Shortwave scheme (Dudhia, 1989) and Goddard scheme (Chou and Suarez, 1994).

Sea Surface Temperature (SST) may be an important parameter for the estimation of heat fluxes and local wind systems in coastal areas, with influence on humidity and rainfall (Alapaty et al., 1995). Given the particular conditions of the modelling domain (Fig. 4), the model response to the usage of time-invariant SST values vs. time-updated SST values was tested. Daily SST values from global NCEP SST analysis with a spatial resolution of $0.5^{\circ}$ were used for the later case.

Four-Dimensional Data Assimilation (FDDA) is a method to limit the growth of errors in a dynamical model, useful

Table 1

Parameters included in the sensitivity analysis

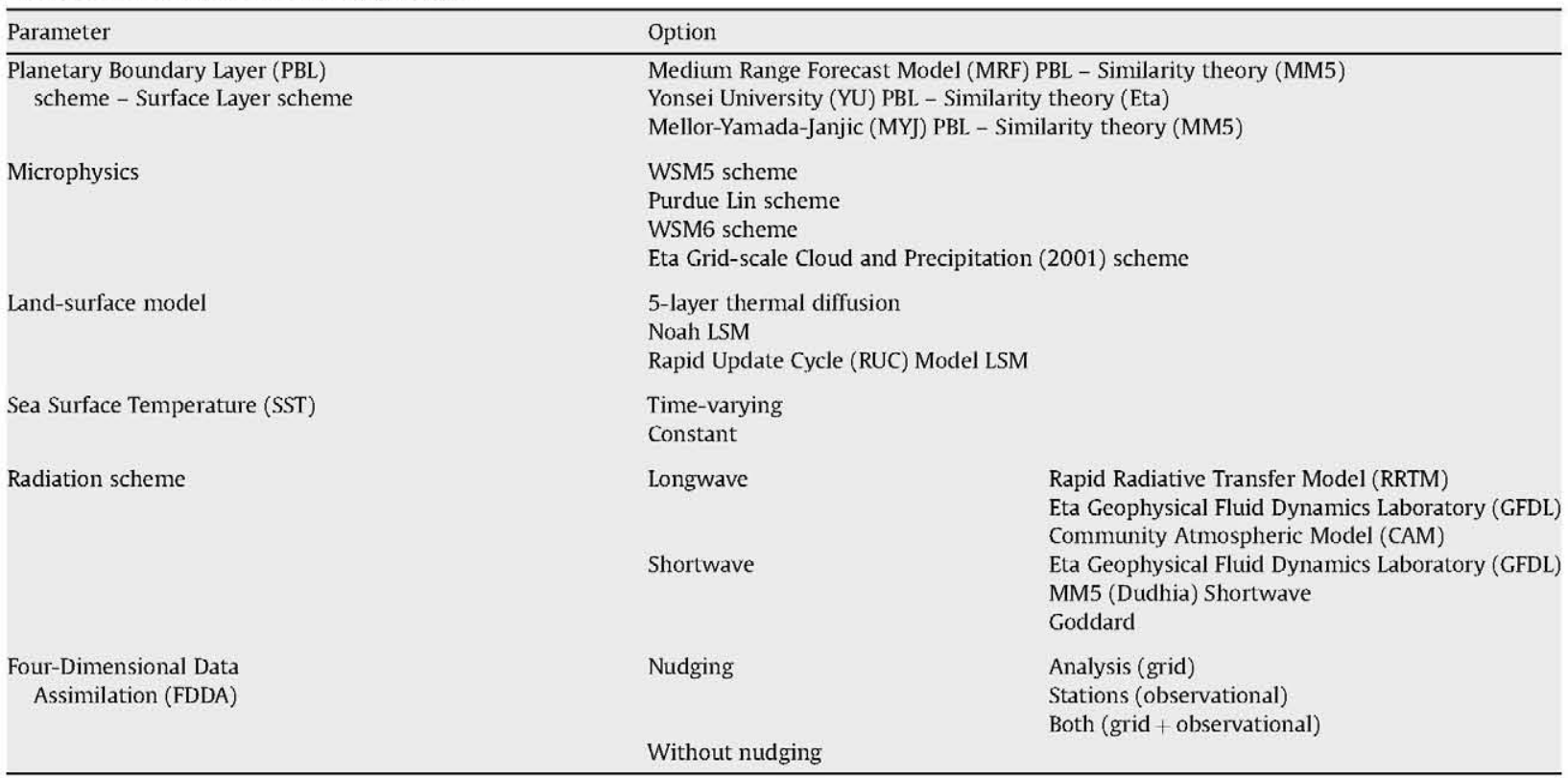




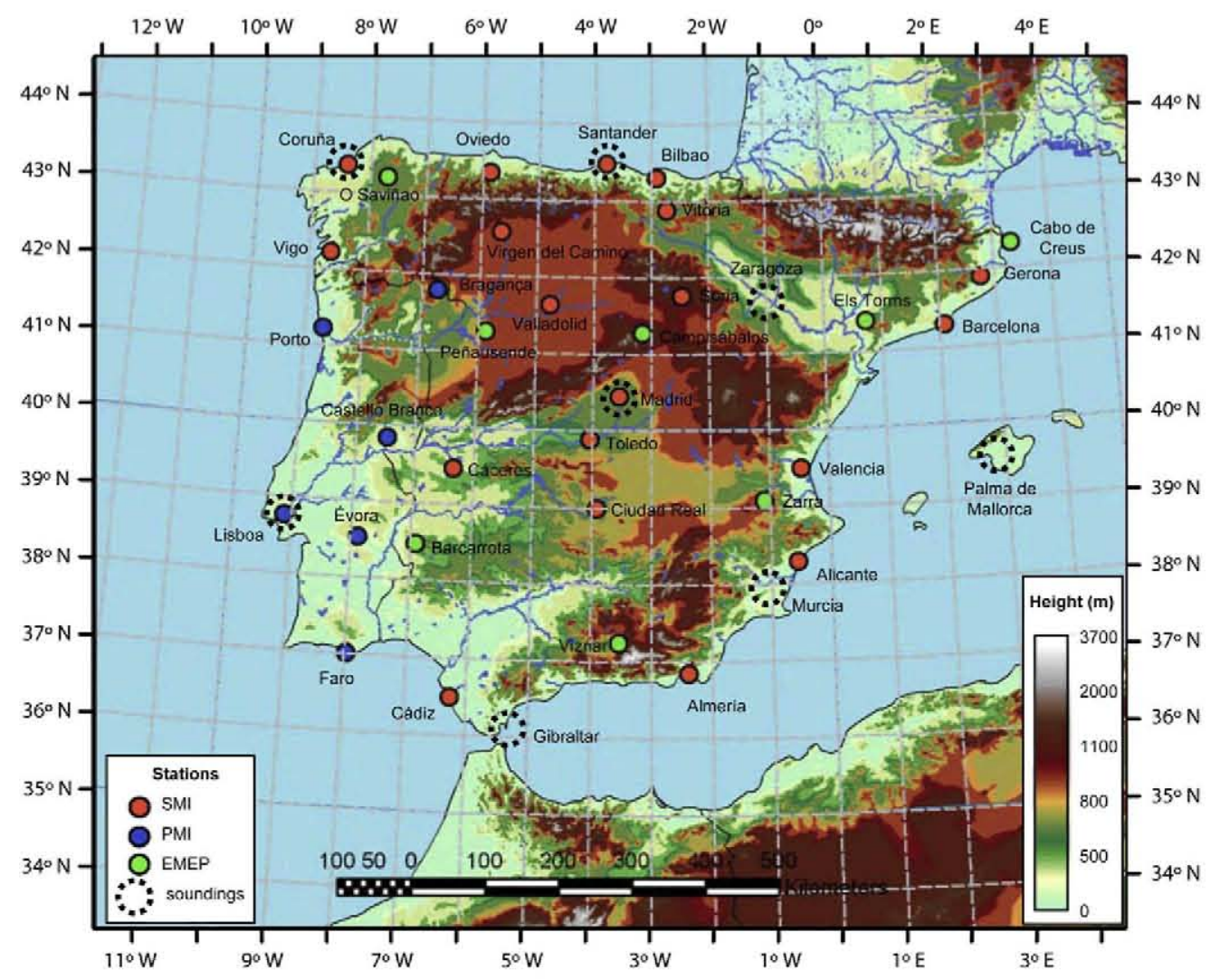

Fig. 4. Meteorological stations selected to perform the sensitivity analysis.

for meteorological applications oriented to air quality modelling (e.g. ozone; Barna and Lamb, 2000), especially in long simulations (Seaman, 2000). The FDDA technique tested in this study is also known as Newtonian relaxation or nudging. When this option is selected, results from the model equations or model state, are relaxed towards the observed values, or observed state. The observed state may be represented by gridded analyses (denoted as grid in Table 1), which are interpolated to the model's current time step (Stauffer and Seaman, 1990), by individual observations from meteorological stations (referred to as observational in Table 1 ), or by a combination of both approaches (grid + observational). A non-physical term has been added to predicted temperature, wind components and moisture according to the default coefficients that control the magnitude of the nudging term $\left(3 \times 10^{-4} \mathrm{~s}^{-1}\right.$ for grid nudging and $6 \times 10^{-4} \mathrm{~s}^{-1}$ when nudging towards observations). Those values assure that the non-physical term added is small compared to the solutions provided by the dynamical equations. No nudging has been applied in the PBL in order to avoid inferences with resolved mesoscale forcing in the model that are important to boundary layer development.

\subsection{Datasets}

The influence of long-range transport and regional meteorological conditions for pollutants such as ozone
(Gangoiti et al., 2002) or particulate matter (Borge et al., 2007) has been clearly stated in the area of interest However, the evaluation carried out is focused on the finegrid domain (D3), since the objective of this study is to assess the sensitivity of the model for high-resolution simulations. Fig. 4 shows the location of the 37 stations selected to provide the meteorological observations. These monitoring sites belong to three different networks: Spanish Meteorological Institute (SMI), Portuguese Meteorological Institute (PMI) and EMEP air quality monitoring network. Stations from the SMI and PMI are part of the main synoptic meteorological network and are generally situated in major cities and airports. The EMEP stations are located in rural areas far from emission sources. Station selection is based on data availability, geophysical conditions and air quality representativity so that the performance of the model can be tested under the broadest range of conditions while restricting the number of stations as much as possible.

\subsection{Evaluation methodology}

From the multiple methodologies available for model evaluation (Gilliam et al., 2006), the classic approach of comparing measurements, mostly surface-based, with model results has been applied, following the definition of model evaluation proposed by Russell and Dennis (2000). This option relies on the idea that domain-wide statistics 
Table 2

Statistics used for model evaluation

\begin{tabular}{llll}
\hline Variable (reference height) & Monitoring network & & \\
\cline { 2 - 4 } & Gross error (E) & Bias error (B) & \multicolumn{1}{c}{$\begin{array}{l}\text { Root mean } \\
\text { square error (RMSE) }\end{array}$} \\
\hline Temperature (2 m) & $X(\leq 2 \mathrm{~K})$ & $X(\leq \pm 0.5 \mathrm{~K})$ & $X\left(\leq 2 \mathrm{~m} \mathrm{~s}^{-1}\right)$ \\
Wind speed $(10 \mathrm{~m})$ & $X\left(\leq \pm 0.5 \mathrm{~m} \mathrm{~s}^{-1}\right)$ & $X(\geq 0.6)$ \\
Wind direction $(10 \mathrm{~m})$ & $X\left(\leq 30^{\circ}\right)$ & $X\left(\leq \pm 10^{\circ}\right)$ & $X\left(\leq \pm 1 \mathrm{~g} \mathrm{~kg}^{-1}\right)$ \\
Humidity $(2 \mathrm{~m})$ & $X\left(\leq 2 \mathrm{~g} \mathrm{~kg}^{-1}\right)$ & $X(\geq 0.6)$ & \\
\hline
\end{tabular}

${ }^{a}$ Calculated following the approach of Gardener and Dorling (2000).

may provide a general performance measure on the capability of the model to replicate observed values, and therefore to minimize input errors to the chemicaltransport model. The statistics selected to drive the evaluation are taken from Emery et al. (2001). According to this methodology, specifically developed to evaluate mesoscale meteorological simulations for air quality purposes, meaningful indexes are proposed for the most relevant parameters as summarized in Table 2 . The original methodology provides a series of benchmarks along with the definition of the statistics (values in brackets in Table 2). It should be noted, however, that they have not been explicitly considered in this study, mainly oriented to find out the best settings for the WRF rather than assessing its performance in absolute values.

Temperature $(\mathrm{K})$ corresponds to WRF T2 predictions, wind speed $\left(\mathrm{m} \mathrm{s}^{-1}\right)$ and direction $\left(^{\circ}\right)$ are computed from $\mathrm{U} 10$ and V10 and humidity $\left(\mathrm{g} \mathrm{kg}^{-1}\right)$ is obtained from Q2 (water mixing ratio at $2 \mathrm{~m}$ ). Humidity observations are provided as relative values (\%); absolute water mixing ratios are derived from relative humidity, temperature and ground-level pressure values.

In the meteorological stations represented with doted circles in Fig. 4, twice-a-day vertical soundings are performed on a routinely basis. Although the deficiencies of radiosonde soundings from the World Meteorological Organization (WMO) stations for model evaluation have been pointed out previously (Han et al., 2008), these already-available upper-air observations have been used to perform a comparison with model outputs. The PBLH, a rather influential variable when conducting air quality simulations (Athanassiadis et al., 2002), has been estimated from vertical soundings through the Bulk Richardson Number (Rib), with a critical value of 0.3 . As illustrated in Fig. 5, this procedure allows estimating the skills of the different physics to reproduce the PBLH approximately at midnight (00 UTC) and noon (12 UTC). This additional evaluation has been applied for PBL
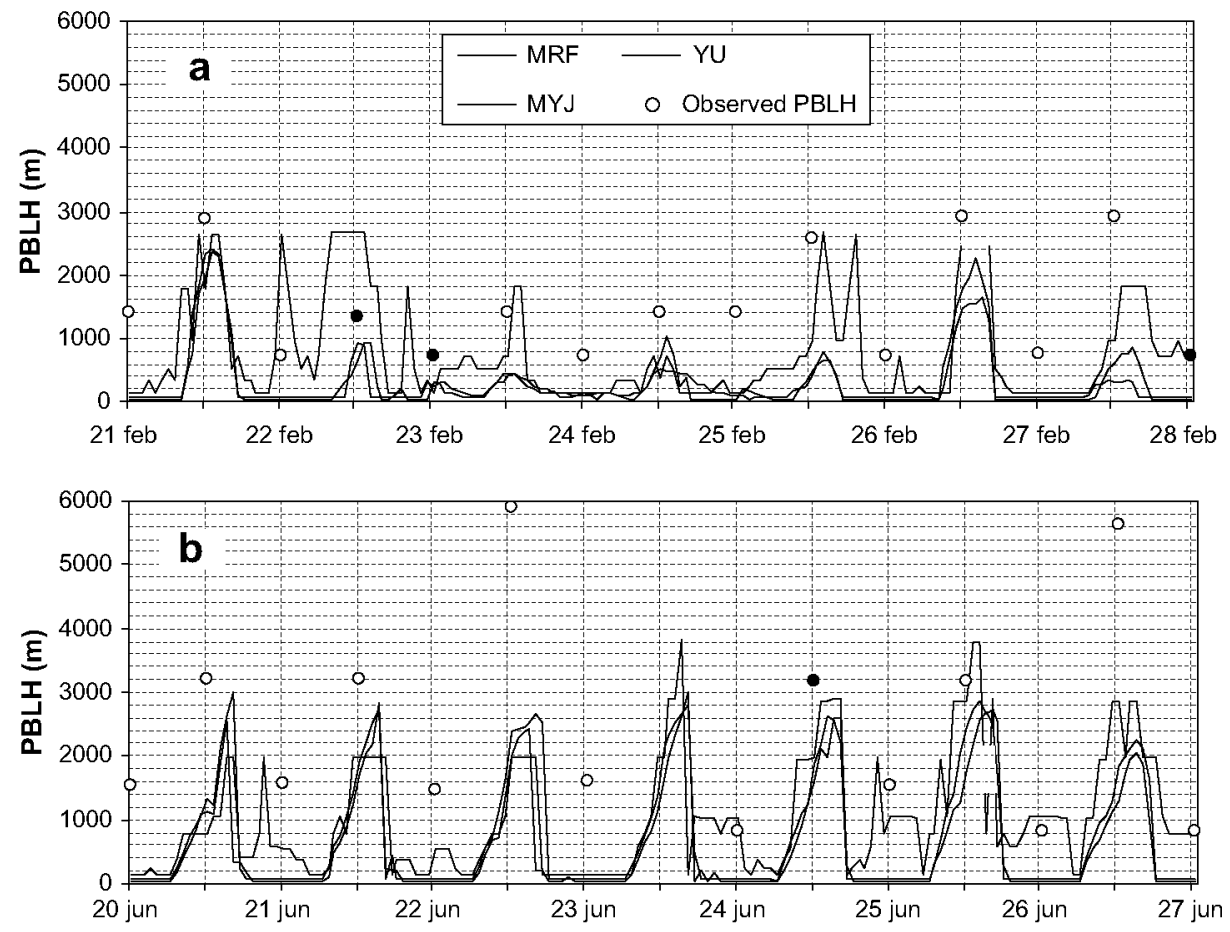

Fig. 5. Comparison of predicted and observed (computed values from vertical soundings using the Bulk Richardson Number) PBLH values under the Planetary Boundary schemes included in the sensitivity analysis. Results for the Madrid station, winter (a) and summer (b) episodes. 
schemes and Land-surface models, in principle, the parameters with the strongest impact on PBLH predictions (Mao et al., 2006; Han et al., 2008).

Results based on the proposed statistics for the experiments listed in Table 1 have been compared for each parameter. Once the best individual options were identified, they were combined into the so-called "best case". This optimal setting was then tested in order to confirm whether the results were actually better than for the rest of experiments.

\section{Results}

Statistical results from the evaluation are shown in this section. Although a detailed analysis at seasonal and monitoring station level has been carried out, only aggregated values are presented. In order to provide a better perspective, the results are shown both at total and monitoring-network level since important differences on model performance have been found depending on the origin of the datasets used for evaluation.

\subsection{PBL scheme}

The YU PBL scheme was found to produce the best statistical results for temperature in every network, except for BE, as shown in Table 3. This physics option is also influential for wind speed, a variable slightly overpredicted under all the PBL options tested. Despite the MRF scheme produced lower $B E\left(0.17 \mathrm{~m} \mathrm{~s}^{-1}\right.$ overall $)$, the results for RMSE and IOA were better when the YU scheme was applied. Wind direction was not clearly influence by the PBL scheme applied, in accordance with the findings of previous sensitivity analysis such as Akylas et al. (2007). The best results for humidity were provided by the MRF with YU scheme close second. Although PBLH predictions were not very sensitive to PBL schemes, the YU provided slightly better results overall. This scheme, developed by Hong et al. (2006) had not been tested before in the Iberian Peninsula as far as authors are aware. According to the results, this option to describe turbulent transport in the boundary layer would improve the performance of other schemes used in the past such as MRF. In this application, both schemes were found to underpredict the PBLH, which contrast with the results of Pérez et al. (2006) for urban coastal areas over the Western Mediterranean. This difference, however, may be largely influenced by the low vertical resolution of observational data and the method used to estimate the PBLH from observations. It should be noted that some underestimations are related to unrealistic "observed" values, such as those illustrated in the example in Fig. 5b; with midday PBLH values beyond $5000 \mathrm{~m}$. In addition, it was observed that PBLH was generally underestimated during nighttime. As discussed in Section 3.3, the different LSM have difficulties in representing the boundary layer evolution under nonconvective conditions. Hence, the underestimation of the PBLH may be partly due to inappropriate vertical heat fluxes representation, although the influence of the diagnosis methods implemented in the PBL schemes to compute PBLH may also play an important role (Han et al.,
Table 3

Statistical evaluation: aggregated results for PBL scheme/surface layer scheme experiments

\begin{tabular}{|c|c|c|c|c|c|c|}
\hline \multirow[t]{2}{*}{ Variable } & \multirow[t]{2}{*}{ Statistic } & \multirow[t]{2}{*}{ Scheme } & \multicolumn{4}{|c|}{ Monitoring network } \\
\hline & & & SMI & EMEP & PMI & Total \\
\hline \multirow[t]{9}{*}{$T$} & \multirow[t]{3}{*}{$\mathrm{BE}(\mathrm{K})$} & MRF & -0.17 & 0.22 & 0.69 & 0.08 \\
\hline & & YU & -0.39 & 0.07 & 0.29 & -0.16 \\
\hline & & MYJ & -1.11 & -0.79 & -0.39 & -0.90 \\
\hline & \multirow[t]{3}{*}{$\mathrm{GE}(\mathrm{K})$} & MRF & 2.30 & 2.45 & 2.41 & 2.35 \\
\hline & & YU & 2.23 & 2.38 & 2.18 & 2.26 \\
\hline & & MYJ & 2.41 & 2.38 & 2.21 & 2.36 \\
\hline & \multirow[t]{3}{*}{ IOA } & MRF & 0.90 & 0.87 & 0.82 & 0.89 \\
\hline & & YU & 0.90 & 0.88 & 0.84 & 0.89 \\
\hline & & MYJ & 0.87 & 0.86 & 0.82 & 0.87 \\
\hline \multirow[t]{9}{*}{ WS } & \multirow[t]{3}{*}{$\mathrm{BE}\left(\mathrm{ms}^{-1}\right)$} & MRF & 0.11 & 0.29 & 0.19 & 0.17 \\
\hline & & YU & 0.23 & 0.24 & 0.07 & 0.20 \\
\hline & & MYJ & 0.47 & 0.49 & 0.41 & 0.46 \\
\hline & \multirow[t]{3}{*}{$\operatorname{RMSE}\left(\mathrm{ms}^{-1}\right)$} & MRF & 2.49 & 3.31 & 2.40 & 2.70 \\
\hline & & YU & 2.47 & 3.20 & 2.12 & 2.61 \\
\hline & & MYJ & 2.70 & 3.17 & 2.32 & 2.76 \\
\hline & \multirow[t]{3}{*}{ IAO } & MRF & 0.62 & 0.70 & 0.61 & 0.66 \\
\hline & & YU & 0.63 & 0.74 & 0.66 & 0.69 \\
\hline & & MYJ & 0.59 & 0.75 & 0.64 & 0.67 \\
\hline \multirow[t]{6}{*}{ WD } & \multirow[t]{3}{*}{$\mathrm{BE}\left(^{\circ}\right)$} & MRF & -12.80 & -11.83 & -25.84 & -15.48 \\
\hline & & YU & -12.02 & -7.94 & -25.31 & -13.94 \\
\hline & & MYJ & -12.48 & -8.71 & -17.40 & -12.86 \\
\hline & \multirow[t]{3}{*}{ GE $\left(^{\circ}\right)$} & MRF & 60.78 & 59.44 & 65.26 & 63.20 \\
\hline & & YU & 60.66 & 57.97 & 64.10 & 62.52 \\
\hline & & MYJ & 61.97 & 60.07 & 62.10 & 63.44 \\
\hline \multirow[t]{9}{*}{$Q$} & \multirow[t]{3}{*}{$\mathrm{BE}\left(\mathrm{g} \mathrm{kg}^{-1}\right)$} & MRF & 1.17 & 1.46 & 1.71 & 1.50 \\
\hline & & YU & 1.25 & 1.63 & 1.94 & 1.67 \\
\hline & & MYJ & 2.06 & 2.30 & 2.64 & 2.38 \\
\hline & \multirow[t]{3}{*}{$\mathrm{GE}\left(\mathrm{g} \mathrm{kg}^{-1}\right)$} & MRF & 2.03 & 2.09 & 2.21 & 2.12 \\
\hline & & YU & 2.06 & 2.10 & 2.30 & 2.16 \\
\hline & & MYJ & 2.46 & 2.55 & 2.76 & 2.60 \\
\hline & \multirow[t]{3}{*}{ IOA } & MRF & 0.48 & 0.53 & 0.49 & 0.52 \\
\hline & & YU & 0.47 & 0.53 & 0.48 & 0.52 \\
\hline & & MYJ & 0.45 & 0.44 & 0.41 & 0.44 \\
\hline
\end{tabular}

2008). In the comparison illustrated in Fig. 5 can be seen that the PBL schemes that compute PBLH as a function of the critical Rib (MRF and YU) tend to define nighttime mixing height to be equal to the height of the first model level. TKE-based schemes such as MYJ overcome this difficulty.

\subsection{Microphysics}

The WSM6 scheme produced the lowest aggregated BE for temperature $(0.05 \mathrm{~K})$, while no conclusive differences were observed for GE and IOA for this parameter, as can be seen in Table 4 . This scheme minimized wind speed BE for most of the stations $\left(0.10 \mathrm{~m} \mathrm{~s}^{-1}\right.$ overall), but produced slightly worse results for wind speed RMSE and IOA than the Eta GCP scheme. No significant differences were found for wind direction predictions depending on the microphysics. The impact on predicted water mixing ratios near the surface was also very small, with absolute humidity bias error ranging from $1.36 \mathrm{~g} \mathrm{~kg}^{-1}$ (Eta GCP) to $1.50 \mathrm{~g} \mathrm{~kg}^{-1}$ (WSM5). This option however, it is considered to be highly influential for precipitation outputs and therefore wet deposition predictions (Queen and Zhang, 2008). According to the results in Table 4, the WSM6 scheme was selected, 
Table 4

Statistical evaluation: aggregated results for Microphysics experiments

\begin{tabular}{|c|c|c|c|c|c|c|}
\hline \multirow[t]{2}{*}{ Variable } & \multirow[t]{2}{*}{ Statistic } & \multirow[t]{2}{*}{ Scheme } & \multicolumn{4}{|c|}{ Monitoring network } \\
\hline & & & SMI & EMEP & PMl & Total \\
\hline \multirow[t]{12}{*}{$\bar{T}$} & \multirow[t]{4}{*}{$\mathrm{BE}(\mathrm{K})$} & WSM 5 & -0.17 & 0.22 & 0.69 & 0.08 \\
\hline & & Lin & -0.07 & 0.38 & 0.67 & 0.17 \\
\hline & & WSM 6 & -0.20 & 0.21 & 0.65 & 0.05 \\
\hline & & Eta GCP & 0.03 & 0.47 & 0.76 & 0.26 \\
\hline & \multirow[t]{4}{*}{$\mathrm{GE}(\mathrm{K})$} & WSM 5 & 2.30 & 2.45 & 2.41 & 2.35 \\
\hline & & Lin & 2.35 & 2.53 & 2.37 & 2.40 \\
\hline & & WSM 6 & 2.31 & 2.43 & 2.39 & 2.36 \\
\hline & & Eta GCP & 2.33 & 2.48 & 2.33 & 2.37 \\
\hline & \multirow[t]{4}{*}{ IOA } & WSM 5 & 0.90 & 0.87 & 0.82 & 0.89 \\
\hline & & Lin & 0.90 & 0.87 & 0.83 & 0.89 \\
\hline & & WSM 6 & 0.90 & 0.87 & 0.83 & 0.89 \\
\hline & & Eta GCP & 0.90 & 0.87 & 0.84 & 0.89 \\
\hline \multirow[t]{12}{*}{ WS } & \multirow[t]{4}{*}{$\mathrm{BE}\left(\mathrm{ms}^{-1}\right)$} & WSM 5 & 0.11 & 0.29 & 0.19 & 0.17 \\
\hline & & Lin & 0.12 & 0.25 & 0.09 & 0.15 \\
\hline & & WSM 6 & 0.07 & 0.15 & 0.14 & 0.10 \\
\hline & & Eta GCP & 0.22 & 0.33 & 0.15 & 0.23 \\
\hline & \multirow[t]{4}{*}{ RMSE $\left(\mathrm{m} \mathrm{s}^{-1}\right)$} & WSM 5 & 2.49 & 3.31 & 2.40 & 2.70 \\
\hline & & Lin & 2.48 & 3.31 & 2.32 & 2.68 \\
\hline & & WSM 6 & 2.50 & 3.23 & 2.33 & 2.67 \\
\hline & & Eta GCP & 2.48 & 3.22 & 2.23 & 2.64 \\
\hline & \multirow[t]{4}{*}{ IAO } & WSM 5 & 0.62 & 0.70 & 0.61 & 0.66 \\
\hline & & Lin & 0.64 & 0.70 & 0.62 & 0.67 \\
\hline & & WSM 6 & 0.61 & 0.71 & 0.62 & 0.66 \\
\hline & & Eta GCP & 0.64 & 0.74 & 0.66 & 0.69 \\
\hline \multirow[t]{8}{*}{ WD } & \multirow[t]{4}{*}{$\mathrm{BE}\left({ }^{\circ}\right)$} & WSM 5 & -12.80 & -11.83 & -25.84 & -15.48 \\
\hline & & Lin & -14.44 & -11.40 & -28.23 & -16.79 \\
\hline & & WSM 6 & -12.79 & -10.16 & -27.00 & -15.28 \\
\hline & & Eta GCP & -14.90 & -12.28 & -29.38 & -17.51 \\
\hline & \multirow[t]{4}{*}{$\operatorname{GE}\left(^{\circ}\right)$} & WSM 5 & 60.78 & 59.44 & 65.26 & 63.20 \\
\hline & & $\operatorname{Lin}$ & 60.44 & 58.69 & 64.08 & 62.58 \\
\hline & & WSM 6 & 61.05 & 58.31 & 65.17 & 63.05 \\
\hline & & Eta GCP & 60.28 & 59.31 & 62.57 & 62.35 \\
\hline \multirow[t]{12}{*}{$Q$} & \multirow[t]{4}{*}{$\mathrm{BE}\left(\mathrm{g} \mathrm{kg}^{-1}\right)$} & WSM 5 & 1.17 & 1.46 & 1.71 & 1.50 \\
\hline & & Lin & 1.10 & 1.41 & 1.60 & 1.42 \\
\hline & & WSM 6 & 1.18 & 1.46 & 1.67 & 1.48 \\
\hline & & Eta GCP & 1.00 & 1.35 & 1.56 & 1.36 \\
\hline & \multirow[t]{4}{*}{$\mathrm{GE}\left(\mathrm{g} \mathrm{kg}^{-1}\right)$} & WSM 5 & 2.03 & 2.09 & 2.21 & 2.12 \\
\hline & & Lin & 1.97 & 2.07 & 2.17 & 2.09 \\
\hline & & WSM 6 & 2.02 & 2.08 & 2.21 & 2.12 \\
\hline & & Eta GCP & 1.95 & 2.09 & 2.16 & 2.09 \\
\hline & \multirow[t]{4}{*}{$\mathrm{IOA}$} & WSM 5 & 0.48 & 0.53 & 0.49 & 0.52 \\
\hline & & Lin & 0.49 & 0.53 & 0.47 & 0.52 \\
\hline & & WSM 6 & 0.48 & 0.52 & 0.47 & 0.52 \\
\hline & & Eta GCP & 0.49 & 0.52 & 0.46 & 0.51 \\
\hline
\end{tabular}

a choice that should be confirmed with precipitation results since this scheme was a $40 \%$ computationally more expensive than WSM 5 according with the experiments carried out in this study.

\subsection{Land-surface model}

The Noah and the 5-layer thermal diffusion land-surface ( $\mathrm{T}$ diff) models produced similar results for temperature, slightly overpredicting $T 2$ values. The 5-layer LSM brought out a smaller BE, but virtually the same GE and IOA as Noah LSM. As for wind speed, the T diff model produced the minimum BE $\left(0.17 \mathrm{~m} \mathrm{~s}^{-1}\right.$ overall) and very similar IOA values to those of the Noah model. Wind direction was relatively poorly predicted for the three schemes, with minimum values of $\mathrm{BE}$ of $15.48^{\circ}$ ( $\mathrm{T}$ diff) and GE of $61.53^{\circ}$
(Noah). The final selection of the Noah LMS was based mostly on the distinct advantage of this option for predicting near-surface water mixing ratios. As summarized in Table 5, this LSM produced sensibly better global figures for all the $Q$ statistics, particularly for the IOA. In accordance with the results of Han et al. (2008), all the LSM exhibited difficulties in representing the boundary layer evolution in the early morning hours. The better overall description of the PBL height evolution was given by the RUC model, closely followed by Noah.

\subsection{SST options}

The figures in Table 6 reflect the small effect of the SST strategy on global results. Temperature BE is smaller when the Sea Surface Temperature is not updated, while the GE is slightly higher and the IOA is insensitive to this option. Although time-dependent SST values do not represent any improvement in the wind field description during the periods simulated, variable-SST was selected since it is a more realistic approach and it expected to have a positive impact on annual runs. Likewise, this option produced little or no improvements as far as humidity is regarded.

\section{Table 5}

Statistical evaluation: aggregated results for Land-surface model experiments

\begin{tabular}{|c|c|c|c|c|c|c|}
\hline \multirow[t]{2}{*}{ Variable } & \multirow[t]{2}{*}{ Statistic } & \multirow[t]{2}{*}{ Scheme } & \multicolumn{4}{|c|}{ Monitoring network } \\
\hline & & & SMI & EMEP & PMI & Total \\
\hline \multirow[t]{9}{*}{$T$} & \multirow[t]{3}{*}{$\mathrm{BE}(\mathrm{K})$} & T diff & -0.17 & 0.22 & 0.69 & 0.08 \\
\hline & & Noah & 0.43 & 1.02 & 1.04 & 0.68 \\
\hline & & RUC & 0.96 & 1.63 & 1.63 & 1.24 \\
\hline & \multirow[t]{3}{*}{ GE $(K)$} & $T$ diff & 2.30 & 2.45 & 2.41 & 2.35 \\
\hline & & Noah & 2.32 & 2.41 & 2.30 & 2.34 \\
\hline & & RUC & 2.42 & 2.74 & 2.77 & 2.56 \\
\hline & \multirow[t]{3}{*}{ IOA } & $T$ diff & 0.90 & 0.87 & 0.82 & 0.89 \\
\hline & & Noah & 0.90 & 0.87 & 0.84 & 0.89 \\
\hline & & RUC & 0.89 & 0.86 & 0.81 & 0.88 \\
\hline \multirow[t]{9}{*}{ WS } & \multirow[t]{3}{*}{$\mathrm{BE}\left(\mathrm{m} \mathrm{s}^{-1}\right)$} & T diff & 0.11 & 0.29 & 0.19 & 0.17 \\
\hline & & Noah & 0.34 & 0.58 & 0.40 & 0.41 \\
\hline & & RUC & 0.31 & 0.59 & 0.48 & 0.41 \\
\hline & \multirow[t]{3}{*}{$\operatorname{RMSE}\left(\mathrm{m} \mathrm{s}^{-1}\right)$} & $T$ diff & 2.49 & 3.31 & 2.40 & 2.70 \\
\hline & & Noah & 2.53 & 3.45 & 2.32 & 2.75 \\
\hline & & RUC & 2.49 & 3.58 & 2.36 & 2.77 \\
\hline & \multirow[t]{3}{*}{ IAO } & T diff & 0.62 & 0.70 & 0.61 & 0.66 \\
\hline & & Noah & 0.63 & 0.69 & 0.65 & 0.66 \\
\hline & & RUC & 0.63 & 0.67 & 0.65 & 0.66 \\
\hline \multirow[t]{6}{*}{ WD } & \multirow[t]{3}{*}{$\mathrm{BE}\left({ }^{\circ}\right)$} & T diff & -12.80 & -11.83 & -25.84 & -15.48 \\
\hline & & Noah & -18.08 & -9.85 & -38.15 & -20.45 \\
\hline & & RUC & -15.54 & -9.22 & -33.96 & -17.99 \\
\hline & \multirow[t]{3}{*}{ GE $\left(^{\circ}\right)$} & $\mathrm{T}$ diff & 60.78 & 59.44 & 65.26 & 63.20 \\
\hline & & Noah & 59.43 & 57.13 & 63.74 & 61.53 \\
\hline & & RUC & 60.34 & 59.84 & 65.23 & 63.04 \\
\hline \multirow[t]{9}{*}{$Q$} & \multirow[t]{3}{*}{$\mathrm{BE}\left(\mathrm{g} \mathrm{kg}^{-1}\right)$} & $T$ diff & 1.17 & 1.46 & 1.71 & 1.50 \\
\hline & & Noah & -0.52 & -0.33 & -0.14 & -0.30 \\
\hline & & RUC & -1.06 & -0.90 & -0.75 & -0.88 \\
\hline & \multirow[t]{3}{*}{$\mathrm{GE}\left(\mathrm{g} \mathrm{kg}^{-1}\right)$} & $T$ diff & 2.03 & 2.09 & 2.21 & 2.12 \\
\hline & & Noah & 1.70 & 1.52 & 1.83 & 1.66 \\
\hline & & RUC & 2.05 & 1.85 & 2.37 & 2.07 \\
\hline & \multirow[t]{3}{*}{ IOA } & $T$ diff & 0.48 & 0.53 & 0.49 & 0.52 \\
\hline & & Noah & 0.54 & 0.68 & 0.57 & 0.63 \\
\hline & & RUC & 0.47 & 0.59 & 0.45 & 0.53 \\
\hline
\end{tabular}


Table 6

Statistical evaluation: aggregated results for Sea Surface Temperature options

\begin{tabular}{|c|c|c|c|c|c|c|}
\hline \multirow[t]{2}{*}{ Variable } & \multirow[t]{2}{*}{ Statistic } & \multirow[t]{2}{*}{ SST option } & \multicolumn{4}{|c|}{ Monitoring network } \\
\hline & & & SMI & EMEP & PMI & Total \\
\hline \multirow[t]{6}{*}{$T$} & \multirow[t]{2}{*}{$\mathrm{BE}(\mathrm{K})$} & Fixed & -0.17 & 0.22 & 0.69 & 0.08 \\
\hline & & Variable & 0.00 & 0.35 & 0.86 & 0.24 \\
\hline & \multirow[t]{2}{*}{$\mathrm{GE}(\mathrm{K})$} & Fixed & 2.30 & 2.45 & 2.41 & 2.35 \\
\hline & & Variable & 2.28 & 2.43 & 2.41 & 2.34 \\
\hline & \multirow[t]{2}{*}{$\mathrm{IOA}$} & Fixed & 0.90 & 0.87 & 0.82 & 0.89 \\
\hline & & Variable & 0.90 & 0.87 & 0.82 & 0.89 \\
\hline \multirow[t]{6}{*}{ WS } & \multirow[t]{2}{*}{$\mathrm{BE}\left(\mathrm{m} \mathrm{s}^{-1}\right)$} & Fixed & 0.11 & 0.29 & 0.19 & 0.17 \\
\hline & & Variable & 0.13 & 0.28 & 0.21 & 0.18 \\
\hline & \multirow[t]{2}{*}{$\operatorname{RMSE}\left(\mathrm{ms}^{-1}\right)$} & Fixed & 2.49 & 3.31 & 2.40 & 2.70 \\
\hline & & Variable & 2.47 & 3.30 & 2.41 & 2.69 \\
\hline & \multirow[t]{2}{*}{ IAO } & Fixed & 0.62 & 0.70 & 0.61 & 0.66 \\
\hline & & Variable & 0.62 & 0.70 & 0.61 & 0.66 \\
\hline \multirow[t]{4}{*}{ WD } & \multirow[t]{2}{*}{$\mathrm{BE}\left({ }^{\circ}\right)$} & Fixed & -12.80 & -11.83 & -25.84 & -15.48 \\
\hline & & Variable & -14.64 & -11.38 & -24.70 & -16.22 \\
\hline & \multirow[t]{2}{*}{$\mathrm{GE}\left(0^{\circ}\right)$} & Fixed & 60.78 & 59.44 & 65.26 & 63.20 \\
\hline & & Variable & 62.19 & 60.08 & 66.30 & 64.38 \\
\hline \multirow[t]{6}{*}{$Q$} & \multirow[t]{2}{*}{$\mathrm{BE}\left(\mathrm{g} \mathrm{kg}^{-1}\right)$} & Fixed & 1.17 & 1.46 & 1.71 & 1.50 \\
\hline & & Variable & 1.21 & 1.54 & 1.76 & 1.55 \\
\hline & \multirow[t]{2}{*}{$\mathrm{GE}\left(\mathrm{g} \mathrm{kg}^{-1}\right)$} & Fixed & 2.03 & 2.09 & 2.21 & 2.12 \\
\hline & & Variable & 2.08 & 2.13 & 2.26 & 2.17 \\
\hline & \multirow[t]{2}{*}{ IOA } & Fixed & 0.48 & 0.53 & 0.49 & 0.52 \\
\hline & & Variable & 0.48 & 0.55 & 0.49 & 0.53 \\
\hline
\end{tabular}

\subsection{Longwave radiation scheme}

The Eta Geophysical Fluid Dynamics Laboratory (GFDL) radiation scheme was selected as the best option to represent longwave radiative fluxes. From the results in Table 7 can be seen that temperature is a parameter very sensitive to longwave schemes, with $\mathrm{BE}$ ranging from 0.08 to $-1.54 \mathrm{~K}$. GFDL scheme provided the best global results for all the statistics as far as temperature is regarded, being RRTM the second best option. Important differences were also found for wind predictions, being CAM scheme clearly less accurate than the other options. GFDL also produced the best results also for wind speed, a variable better depicted during the winter episode. As for wind direction, RRTM and GFDL exhibited similar performance. Results on humidity predictions are not conclusive since CAM, GFDL and RRTM provided the best aggregated results for $B E, G E$ and IOA, respectively.

\subsection{Shortwave radiation scheme}

The MM5 Shortwave scheme (Dudhia) was selected as the best option to resolve shortwave radiation budgets in the atmosphere. Although model temperature predictions are more sensitive to longwave schemes, some differences were observed among the three shortwave schemes tested. Dudhia scheme performed very similarly to GFDL for temperature, but provided a more balanced $\mathrm{BE}$ and better GE. The Dudhia scheme was found to produce slightly worse results for wind speed than the other schemes but provided better results for wind direction, as summarized in Table 8 . None of the schemes provided a clearly better representation of humidity.
Table 7

Statistical evaluation: aggregated results for radiation schemes (longwave) experiments

\begin{tabular}{|c|c|c|c|c|c|c|}
\hline \multirow[t]{2}{*}{ Variable } & \multirow[t]{2}{*}{ Statistic } & \multirow[t]{2}{*}{ Scheme } & \multicolumn{4}{|c|}{ Monitoring network } \\
\hline & & & SMI & EMEP & PMI & Total \\
\hline \multirow[t]{9}{*}{$T$} & \multirow[t]{3}{*}{$\mathrm{BE}(\mathrm{K})$} & RRTM & -0.17 & 0.22 & 0.69 & 0.08 \\
\hline & & GFDL & -0.48 & -0.11 & 0.26 & -0.26 \\
\hline & & CAM & -1.83 & -1.67 & -0.48 & -1.54 \\
\hline & \multirow[t]{3}{*}{$\mathrm{GE}(\mathrm{K})$} & RRTM & 2.30 & 2.45 & 2.41 & 2.35 \\
\hline & & GFDL & 2.14 & 2.19 & 2.14 & 2.15 \\
\hline & & CAM & 3.46 & 3.24 & 2.76 & 3.28 \\
\hline & \multirow[t]{3}{*}{$\mathrm{IOA}$} & RRTM & 0.90 & 0.87 & 0.82 & 0.89 \\
\hline & & GFDL & 0.91 & 0.90 & 0.85 & 0.90 \\
\hline & & CAM & 0.80 & 0.79 & 0.80 & 0.81 \\
\hline \multirow[t]{9}{*}{ WS } & \multirow[t]{3}{*}{$\mathrm{BE}\left(\mathrm{m} \mathrm{s}^{-1}\right)$} & RRTM & 0.11 & 0.29 & 0.19 & 0.17 \\
\hline & & GFDL & 0.09 & 0.18 & 0.05 & 0.10 \\
\hline & & CAM & -0.31 & 0.05 & -0.47 & -0.25 \\
\hline & \multirow[t]{3}{*}{$\operatorname{RMSE}\left(\mathrm{m} \mathrm{s}^{-1}\right)$} & RRTM & 2.49 & 3.31 & 2.40 & 2.70 \\
\hline & & GFDL & 2.51 & 3.16 & 2.20 & 2.63 \\
\hline & & CAM & 2.71 & 3.68 & 2.59 & 2.96 \\
\hline & \multirow[t]{3}{*}{ IAO } & RRTM & 0.62 & 0.70 & 0.61 & 0.66 \\
\hline & & GFDL & 0.62 & 0.75 & 0.64 & 0.68 \\
\hline & & CAM & 0.46 & 0.58 & 0.42 & 0.52 \\
\hline \multirow[t]{6}{*}{ WD } & \multirow[t]{3}{*}{$\mathrm{BE}\left({ }^{\circ}\right)$} & RRTM & -12.80 & -11.83 & -25.84 & -15.48 \\
\hline & & GFDL & -16.23 & -13.01 & -28.27 & -18.25 \\
\hline & & CAM & -21.79 & -19.94 & -31.03 & -23.79 \\
\hline & \multirow[t]{3}{*}{$\operatorname{GE}\left(^{\circ}\right)$} & RRTM & 60.78 & 59.44 & 65.26 & 63.20 \\
\hline & & GFDL & 62.69 & 59.28 & 60.37 & 63.32 \\
\hline & & CAM & 72.73 & 70.94 & 85.46 & 77.01 \\
\hline \multirow[t]{9}{*}{$Q$} & \multirow[t]{3}{*}{$\mathrm{BE}\left(\mathrm{g} \mathrm{kg}^{-1}\right)$} & RRTM & 1.17 & 1.46 & 1.71 & 1.50 \\
\hline & & GFDL & 1.08 & 1.44 & 1.55 & 1.41 \\
\hline & & CAM & 0.89 & 1.16 & 1.59 & 1.26 \\
\hline & \multirow[t]{3}{*}{$\mathrm{GE}\left(\mathrm{g} \mathrm{kg}^{-1}\right)$} & RRTM & 2.03 & 2.09 & 2.21 & 2.12 \\
\hline & & GFDL & 1.94 & 2.06 & 2.11 & 2.06 \\
\hline & & CAM & 2.08 & 1.99 & 2.34 & 2.13 \\
\hline & \multirow[t]{3}{*}{ IOA } & RRTM & 0.48 & 0.53 & 0.49 & 0.52 \\
\hline & & GFDL & 0.48 & 0.51 & 0.45 & 0.50 \\
\hline & & CAM & 0.42 & 0.54 & 0.42 & 0.50 \\
\hline
\end{tabular}

\subsection{FDDA options}

Results for the four nudging strategies tested are shown in Table 9. Combined nudging towards grid and observations ( $\mathrm{Gr}+\mathrm{Obs}$ ) provided the best results for most of the statistics/locations. The results for BE from the no-nudging option were often similar or even better (wind direction for instance). The advantage of this method is generally clear when the GE is analysed. From the results it can be inferred that grid nudging alone is not suitable for fine-grid resolution. This option frequently provided poorer results than when no restrictions are applied to the prognostic equations of the model. Little or no improvement was observed either with observational nudging alone.

\subsection{Best case}

A final sensitivity test was carried out to assess the combined effect of the individual options selected in the previous runs. The results are summarized in Table 10 . This configuration produced the best aggregated values of IOA for temperature, with a global result of 0.90 . Individual statistics for the evaluated locations are shown in Fig. 6. As in most of the sensitivity runs, the model tends to 
Table 8

Statistical evaluation: aggregated results for radiation schemes (shortwave) experiments

\begin{tabular}{|c|c|c|c|c|c|c|}
\hline \multirow[t]{2}{*}{ Variable } & \multirow[t]{2}{*}{ Statistic } & \multirow[t]{2}{*}{ Scheme } & \multicolumn{4}{|c|}{ Monitoring network } \\
\hline & & & SMI & EMEP & PMI & Total \\
\hline \multirow[t]{9}{*}{$T$} & \multirow[t]{3}{*}{$\mathrm{BE}(\mathrm{K})$} & Dudhia & -0.17 & 0.22 & 0.69 & 0.08 \\
\hline & & GFDL & 0.28 & 0.63 & 1.02 & 0.50 \\
\hline & & Goddard & -0.21 & -0.08 & 1.20 & 0.08 \\
\hline & \multirow[t]{3}{*}{$G E(K)$} & Dudhia & 2.30 & 2.45 & 2.41 & 2.35 \\
\hline & & GFDL & 2.35 & 2.56 & 2.59 & 2.44 \\
\hline & & Goddard & 3.02 & 2.93 & 2.86 & 2.97 \\
\hline & \multirow[t]{3}{*}{ IOA } & Dudhia & 0.90 & 0.87 & 0.82 & 0.89 \\
\hline & & GFDL & 0.90 & 0.87 & 0.81 & 0.88 \\
\hline & & Goddard & 0.83 & 0.82 & 0.79 & 0.83 \\
\hline \multirow[t]{9}{*}{ WS } & \multirow[t]{3}{*}{$\mathrm{BE}\left(\mathrm{m} \mathrm{s}^{-1}\right)$} & Dudhia & 0.11 & 0.29 & 0.19 & 0.17 \\
\hline & & GFDL & 0.17 & 0.14 & 0.14 & 0.16 \\
\hline & & Goddard & -0.20 & 0.11 & -0.30 & -0.14 \\
\hline & \multirow[t]{3}{*}{$\operatorname{RMSE}\left(\mathrm{m} \mathrm{s}^{-1}\right)$} & Dudhia & 2.49 & 3.31 & 2.40 & 2.70 \\
\hline & & GFDL & 2.46 & 3.15 & 2.34 & 2.62 \\
\hline & & Goddard & 2.65 & 3.71 & 2.53 & 2.93 \\
\hline & \multirow[t]{3}{*}{ IAO } & Dudhia & 0.62 & 0.70 & 0.61 & 0.66 \\
\hline & & GFDL & 0.62 & 0.72 & 0.64 & 0.67 \\
\hline & & Goddard & 0.48 & 0.57 & 0.45 & 0.53 \\
\hline \multirow[t]{6}{*}{ WD } & \multirow[t]{3}{*}{$\mathrm{BE}\left({ }^{\circ}\right)$} & Dudhia & -12.80 & -11.83 & -25.84 & -15.48 \\
\hline & & GFDL & -13.62 & -11.63 & -27.48 & -16.23 \\
\hline & & Goddard & -25.34 & -17.39 & -32.95 & -25.58 \\
\hline & \multirow[t]{3}{*}{ GE $\left({ }^{\circ}\right)$} & Dudhia & 60.78 & 59.44 & 65.26 & 63.20 \\
\hline & & GFDL & 61.64 & 60.00 & 65.40 & 63.87 \\
\hline & & Goddard & 73.53 & 69.13 & 79.36 & 75.83 \\
\hline \multirow[t]{9}{*}{$Q$} & \multirow[t]{3}{*}{$\mathrm{BE}\left(\mathrm{g} \mathrm{kg^{-1 }}\right)$} & Dudhia & 1.17 & 1.46 & 1.71 & 1.50 \\
\hline & & GFDL & 1.07 & 1.44 & 1.67 & 1.45 \\
\hline & & Goddard & 0.50 & 0.93 & 1.29 & 0.98 \\
\hline & \multirow[t]{3}{*}{$\mathrm{GE}\left(\mathrm{g} \mathrm{kg}^{-1}\right)$} & Dudhia & 2.03 & 2.09 & 2.21 & 2.12 \\
\hline & & GFDL & 1.93 & 2.11 & 2.19 & 2.11 \\
\hline & & Goddard & 2.13 & 2.08 & 2.33 & 2.18 \\
\hline & \multirow[t]{3}{*}{$10 \mathrm{~A}$} & Dudhia & 0.48 & 0.53 & 0.49 & 0.52 \\
\hline & & GFDL & 0.52 & 0.54 & 0.49 & 0.53 \\
\hline & & Goddard & 0.41 & 0.52 & 0.41 & 0.49 \\
\hline
\end{tabular}

overpredict temperature in winter and underpredict it in summer (Fig. 6a), being the magnitude of the errors similar (Fig. 6b). From the station-level IOA results shown in Fig. 6c can be inferred that temperature tendencies are better depicted by the model in summer, especially for the EMEP stations. The skills of WRF to reproduce wind speed were distinctly improved under these settings. As reflected in Table 10 , a global IOA of 0.72 is achieved, along with the best results for $B E\left(-0.07 \mathrm{~m} \mathrm{~s}^{-1}\right)$ and RMSE $\left(2.40 \mathrm{~m} \mathrm{~s}^{-1}\right)$. The details of the seasonal and spatial distribution of biases and errors for wind speed are shown in Fig. 7. From Fig. 7a can be seen that $\mathrm{BE}$ at station level range from -1.5 to $1.5 \mathrm{~m} \mathrm{~s}^{-1}$ except for some stations in the winter simulation. Wind speed was grossly overestimated in Cadiz $\left(\mathrm{BE}=4.7 \mathrm{~m} \mathrm{~s}^{-1}\right)$ during the whole episode. This may be related to observations since other relatively high $B E$ values such as those of Gerona or Faro (2.5 and $2.3 \mathrm{~m} \mathrm{~s}^{-1}$, respectively) were due to a few but large discrepancies. The model shows a reasonable performance for RMSE as well (Fig. 7b) except for the abovementioned stations and some other coastal locations such as Cabo de Creus (RMSE $=5.6 \mathrm{~m} \mathrm{~s}^{-1}$ ), were the model failed to replicate maximum observed speed values, up to $25 \mathrm{~ms}^{-1}$. The temporal agreement between observed and predicted values for all the other stations is reasonable and rather
Table 9

Statistical evaluation: aggregated results for FDDA experiments

\begin{tabular}{|c|c|c|c|c|c|c|}
\hline \multirow[t]{2}{*}{ Variable } & \multirow[t]{2}{*}{ Statistic } & \multirow[t]{2}{*}{ Nudging option ${ }^{a}$} & \multicolumn{4}{|c|}{ Monitoring network } \\
\hline & & & SMI & EMEP & PMI & Total \\
\hline \multirow[t]{12}{*}{$T$} & $\mathrm{BE}(\mathrm{K})$ & None & -0.17 & 0.22 & 0.69 & 0.08 \\
\hline & & Gr & -0.78 & -0.65 & 0.74 & -0.47 \\
\hline & & Obs & -0.16 & 0.23 & 0.71 & 0.09 \\
\hline & & $\mathrm{Gr}+\mathrm{Obs}$ & -0.33 & 0.26 & 0.28 & -0.08 \\
\hline & GE (K) & None & 2.30 & 2.45 & 2.41 & 2.35 \\
\hline & & $\mathrm{Gr}$ & 3.10 & 2.88 & 2.77 & 2.99 \\
\hline & & Obs & 2.29 & 2.45 & 2.40 & 2.35 \\
\hline & & $\mathrm{Gr}+$ Obs & 2.18 & 2.23 & 2.22 & 2.20 \\
\hline & $10 \mathrm{~A}$ & None & 0.90 & 0.87 & 0.82 & 0.89 \\
\hline & & Gr & 0.81 & 0.82 & 0.79 & 0.82 \\
\hline & & Obs & 0.90 & 0.87 & 0.82 & 0.89 \\
\hline & & $\mathrm{Gr}+$ Obs & 0.91 & 0.89 & 0.84 & 0.90 \\
\hline \multirow[t]{12}{*}{ WS } & $\mathrm{BE}\left(\mathrm{m} \mathrm{s}^{-1}\right)$ & None & 0.11 & 0.29 & 0.19 & 0.17 \\
\hline & & Gr & -0.56 & -0.20 & -0.59 & -0.47 \\
\hline & & Obs & 0.12 & 0.27 & 0.19 & 0.17 \\
\hline & & $\mathrm{Gr}+\mathrm{Obs}$ & 0.19 & 0.12 & 0.07 & 0.15 \\
\hline & $\operatorname{RMSE}\left(\mathrm{m} \mathrm{s}^{-1}\right)$ & None & 2.49 & 3.31 & 2.40 & 2.70 \\
\hline & & $\mathrm{Gr}$ & 2.58 & 3.79 & 2.49 & 2.91 \\
\hline & & Obs & 2.49 & 3.34 & 2.40 & 2.71 \\
\hline & & $\mathrm{Gr}+$ Obs & 2.46 & 3.09 & 2.26 & 2.59 \\
\hline & IAO & None & 0.62 & 0.70 & 0.61 & 0.66 \\
\hline & & $\mathrm{Gr}$ & 0.47 & 0.53 & 0.47 & 0.51 \\
\hline & & Obs & 0.61 & 0.70 & 0.61 & 0.66 \\
\hline & & $\mathrm{Gr}+\mathrm{Obs}$ & 0.65 & 0.72 & 0.66 & 0.68 \\
\hline \multirow[t]{8}{*}{ WD } & $\mathrm{BE}\left({ }^{\circ}\right)$ & None & -12.80 & -11.83 & -25.84 & -15.48 \\
\hline & & Gr & -28.79 & -21.99 & -38.33 & -29.81 \\
\hline & & Obs & -13.39 & -12.21 & -26.06 & -15.97 \\
\hline & & $\mathrm{Gr}+\mathrm{Obs}$ & -16.93 & -14.63 & -31.70 & -19.74 \\
\hline & $\mathrm{GE}\left({ }^{\circ}\right)$ & None & 60.78 & 59.44 & 65.26 & 63.20 \\
\hline & & $\mathrm{Gr}$ & 75.75 & 72.85 & 84.07 & 78.98 \\
\hline & & Obs & 60.85 & 59.12 & 65.20 & 63.15 \\
\hline & & $\mathrm{Gr}+\mathrm{Obs}$ & 58.97 & 58.53 & 62.49 & 61.37 \\
\hline \multirow[t]{12}{*}{ Q } & $\mathrm{BE}\left(\mathrm{g} \mathrm{kg}^{-1}\right)$ & None & 1.17 & 1.46 & 1.71 & 1.50 \\
\hline & & Gr & 0.67 & 1.06 & 1.26 & 1.06 \\
\hline & & Obs & 1.17 & 1.46 & 1.69 & 1.48 \\
\hline & & $\mathrm{Gr}+\mathrm{Obs}$ & 1.08 & 1.31 & 1.44 & 1.31 \\
\hline & $\mathrm{GE}\left(\mathrm{g} \mathrm{kg}^{-1}\right)$ & None & 2.03 & 2.09 & 2.21 & 2.12 \\
\hline & & $\mathrm{Gr}$ & 2.20 & 2.04 & 2.33 & 2.17 \\
\hline & & Obs & 2.03 & 2.09 & 2.21 & 2.12 \\
\hline & & $\mathrm{Gr}+\mathrm{Obs}$ & 1.89 & 1.95 & 2.02 & 1.96 \\
\hline & $\mathrm{IOA}$ & None & 0.48 & 0.53 & 0.49 & 0.52 \\
\hline & & $\mathrm{Gr}$ & 0.37 & 0.54 & 0.35 & 0.47 \\
\hline & & Obs & 0.48 & 0.53 & 0.49 & 0.25 \\
\hline & & $\mathrm{Gr}+\mathrm{Obs}$ & 0.47 & 0.54 & 0.48 & 0.52 \\
\hline
\end{tabular}

${ }^{a}$ Gr - grid nudging, Obs - observational nudging.

Table 10

Model performance for the optimal configuration (best case)

\begin{tabular}{|c|c|c|c|c|c|}
\hline \multirow[t]{2}{*}{ Variable } & \multirow[t]{2}{*}{ Statistic } & \multicolumn{4}{|c|}{ Monitoring network } \\
\hline & & SMI & EMEP & PMI & Total \\
\hline $\bar{T}$ & $\begin{array}{l}\text { BE (K) } \\
\text { GE (K) } \\
\text { IOA }\end{array}$ & $\begin{array}{r}-0.11 \\
2.17 \\
0.91\end{array}$ & $\begin{array}{l}0.89 \\
2.27 \\
0.89\end{array}$ & $\begin{array}{l}0.10 \\
2.06 \\
0.86\end{array}$ & $\begin{array}{l}0.16 \\
2.17 \\
0.90\end{array}$ \\
\hline WS & $\begin{array}{l}\operatorname{BE}\left(\mathrm{m} \mathrm{s}^{-1}\right) \\
\text { RMSE }\left(\mathrm{m} \mathrm{s}^{-1}\right) \\
\text { IAO }\end{array}$ & $\begin{array}{r}-0.01 \\
2.35 \\
0.65\end{array}$ & $\begin{array}{r}-0.19 \\
2.81 \\
0.77\end{array}$ & $\begin{array}{r}-0.13 \\
1.94 \\
0.73\end{array}$ & $\begin{array}{r}-0.07 \\
2.40 \\
0.72\end{array}$ \\
\hline WD & $\begin{array}{l}\mathrm{BE}\left(^{\circ}\right) \\
\operatorname{GE}\left(^{\circ}\right)\end{array}$ & $\begin{array}{r}-20.50 \\
58.51\end{array}$ & $\begin{array}{r}-14.41 \\
55.91\end{array}$ & $\begin{array}{r}-36.15 \\
63.69\end{array}$ & $\begin{array}{r}-22.62 \\
60.67\end{array}$ \\
\hline Q & $\begin{array}{l}\mathrm{BE}\left(\mathrm{g} \mathrm{kg}^{-1}\right) \\
\mathrm{GE}\left(\mathrm{g} \mathrm{kg}^{-1}\right) \\
\mathrm{IOA}\end{array}$ & $\begin{array}{r}-0.43 \\
1.64 \\
0.56\end{array}$ & $\begin{array}{r}-0.65 \\
1.58 \\
0.67\end{array}$ & $\begin{array}{l}0.25 \\
1.69 \\
0.60\end{array}$ & $\begin{array}{r}-0.29 \\
1.63 \\
0.63\end{array}$ \\
\hline
\end{tabular}


a

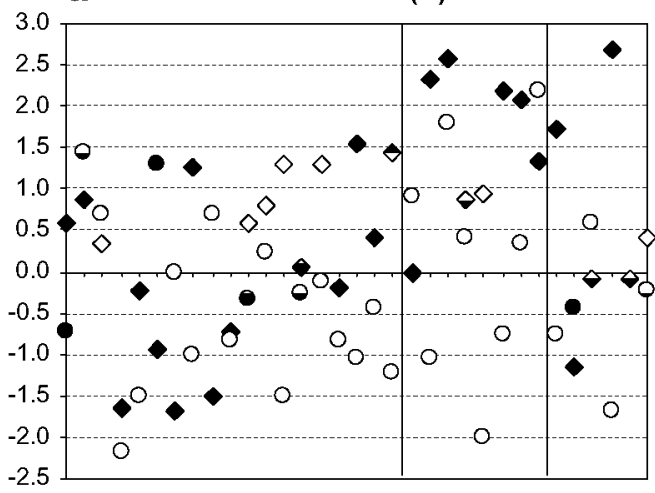

b
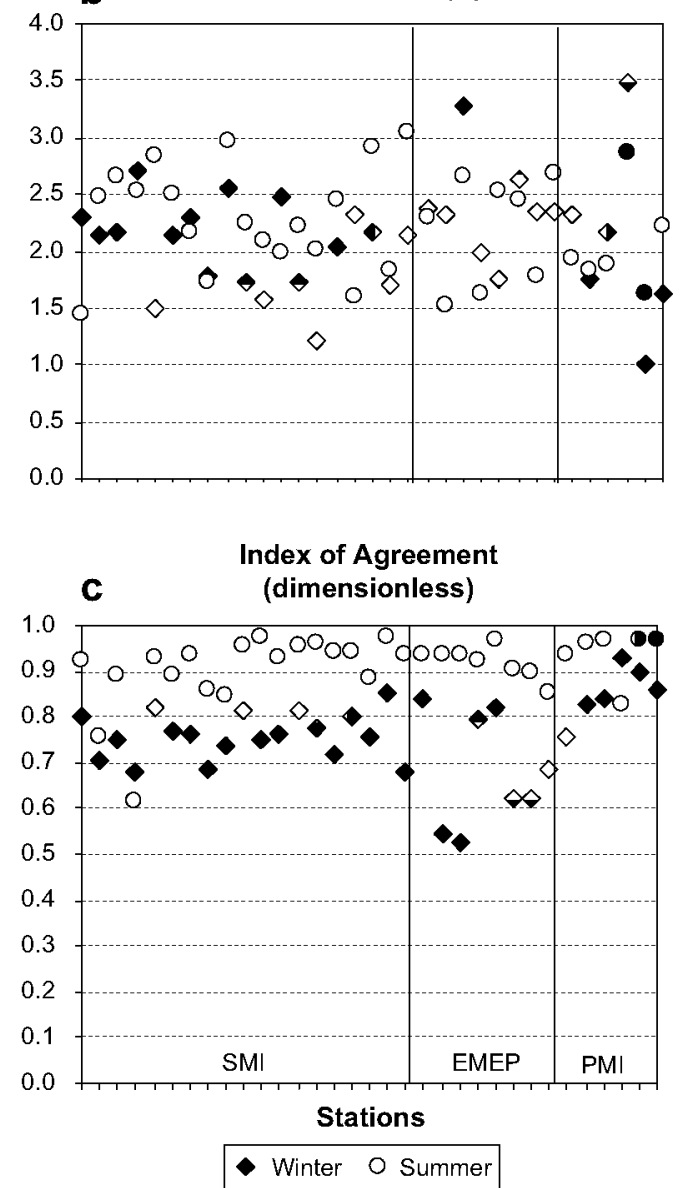

Fig. 6. Station-level statistics for the best case for winter and summer. Temperature results: BE (a), GE (b) and IOA (c).

consistent in the two episodes simulated as shown in Fig. $7 \mathrm{c}$. Although still producing relatively poor results for wind direction, the best case minimized total GE. The model however, performs differently depending on the network. The aggregated BE for the PMI stations doubles the corresponding value for the Spanish area. Fig. 8 illustrates how the bias (Fig. 8a) and absolute errors (Fig. 8b) are spatially distributed. Wind predictions are biased in the a

Bias Error $(\mathrm{m} / \mathrm{s})$

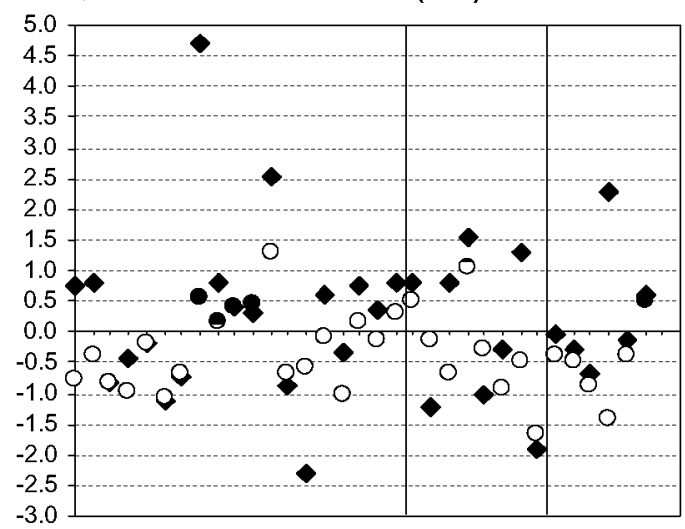

b Root Mean Square Error $(\mathrm{m} / \mathrm{s})$
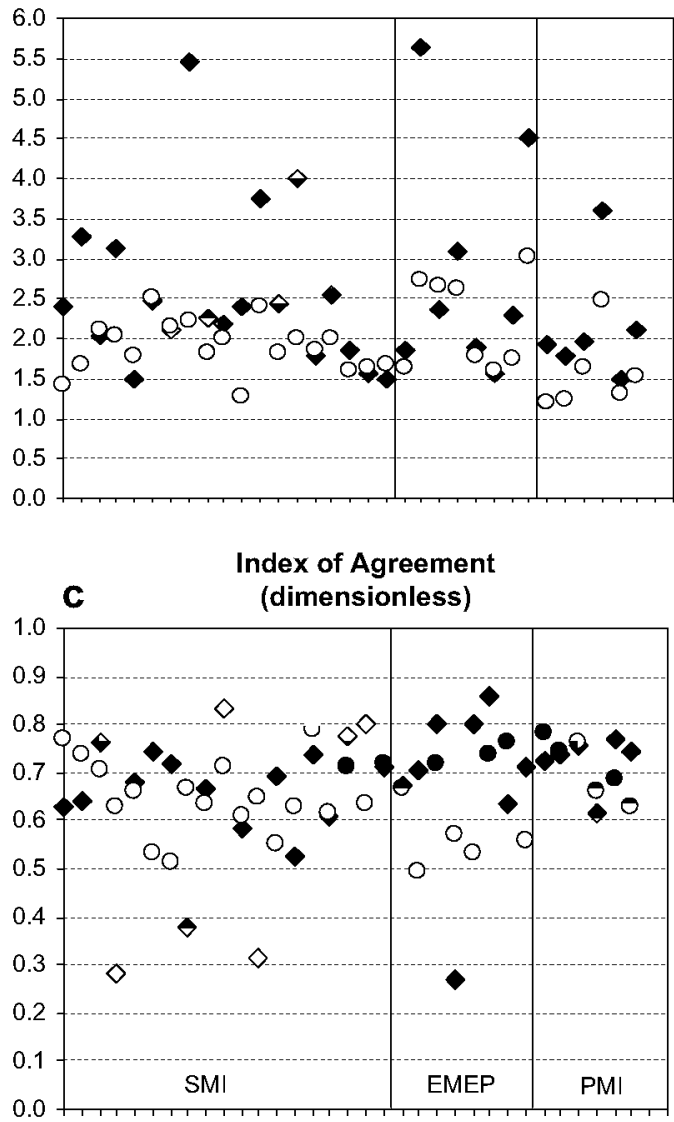

Stations

Winter O Summer

Fig. 7. Station-level statistics for the best case for winter and summer. Wind speed results: BE (a), RMSE (b) and IOA (c).

same direction for most of the stations. This error seems to be systematic for the PMI stations, producing a very small spread in GE. Those stations, however, are located in rather heterogeneous areas (see map in Fig. 4), so that the reason of larger errors may be related to different measuring procedures. 

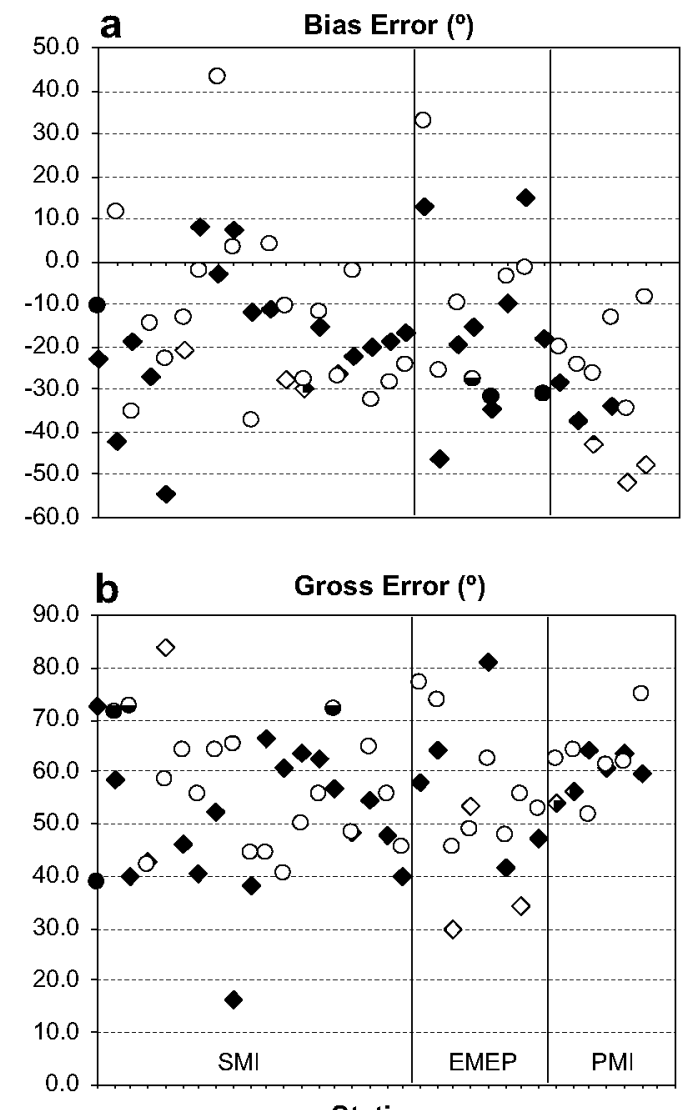

Stations

- Winter o Summer

Fig. 8. Station-level statistics for the best case for winter and summer. Wind direction results: BE (a), and GE (b).

Moisture performance metrics obtained for the best case are notably better than those corresponding to any other configuration that does not include the Noah LSM. As shown in Table 10, a global IOA of 0.63 is reached. Nevertheless, from the detailed results reflected in Fig. 9 can be seen that the model performs clearly differently depending on the season. The accuracy of $Q$ predictions decreases in summer, especially for dry locations. The largest discrepancy between observed and predicted humidity is observed in the Almería station (the driest area in Europe), with a $\mathrm{BE}$ in summer of $-8 \mathrm{~g} \mathrm{~kg}^{-1}$ (Fig. 9a). This underprediction is systematic since the magnitude of the GE is quite similar (Fig. 9b). Although $Q$ is strongly underpredicted under such conditions, the IOA is not particularly low (Fig. 9c), so the temporal evolution of humidity is acceptably described. Consequently, the poorer behaviour of WRF in summer may be due not to the LSM itself, but to the inputs regarding soil moisture, a critical parameter to obtain an accurate representation of the land-surface water fluxes (Kumar et al., 2008).

Fig. 10 provides an example of model performance for PBLH in two significant stations, Madrid (Fig. 10a) in the centre of the Peninsula, and Murcia (Fig. 10b) close to the Mediterranean Sea. These graphs compare the results
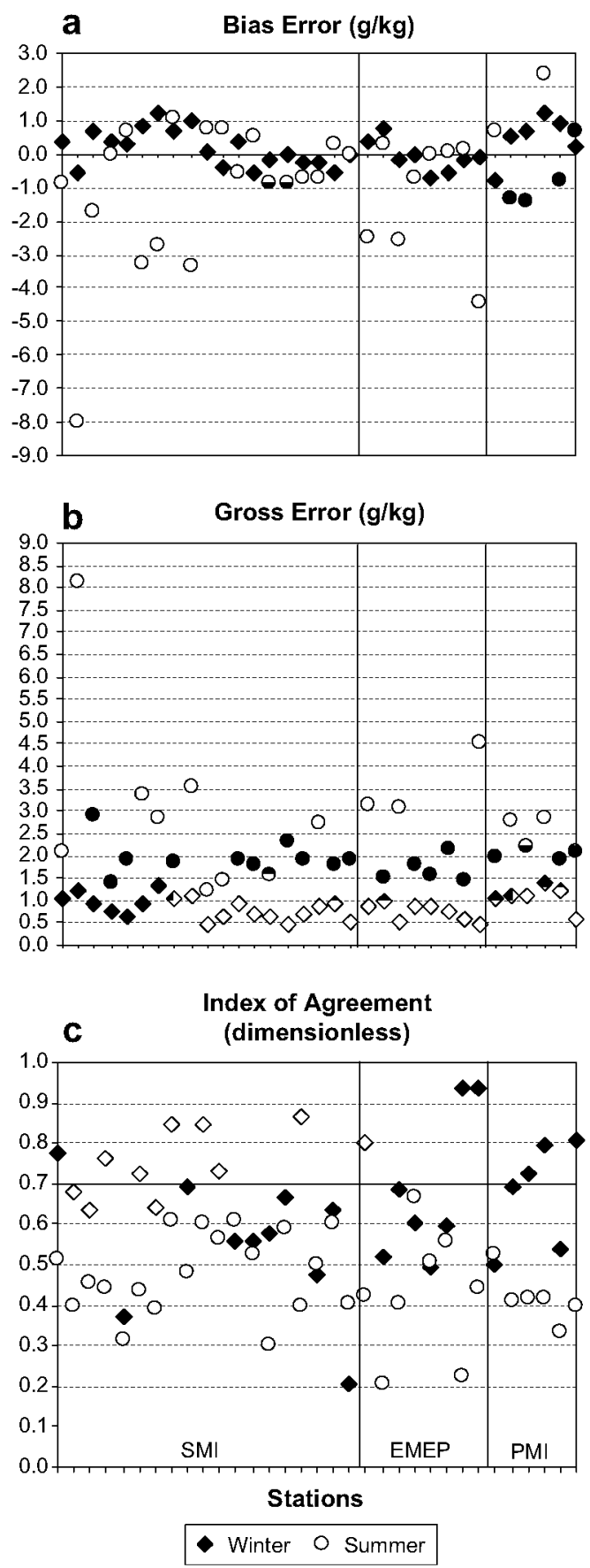

Fig. 9. Station-level statistics for the best case for winter and summer. Humidity results: BE (a), GE (b) and IOA (c).

obtained from the sensitivity runs performed for PBL and LSM schemes, the best case and the PBLH values derived from soundings at 00 UTC and 12 UTC. The best case did not improve the poor representation of the boundary layer during the night pointed out in Section 3.1. As for the PBLH estimations around midday, the best case configuration brought about lower estimates than the other experiments for winter, but provided the best agreement with 

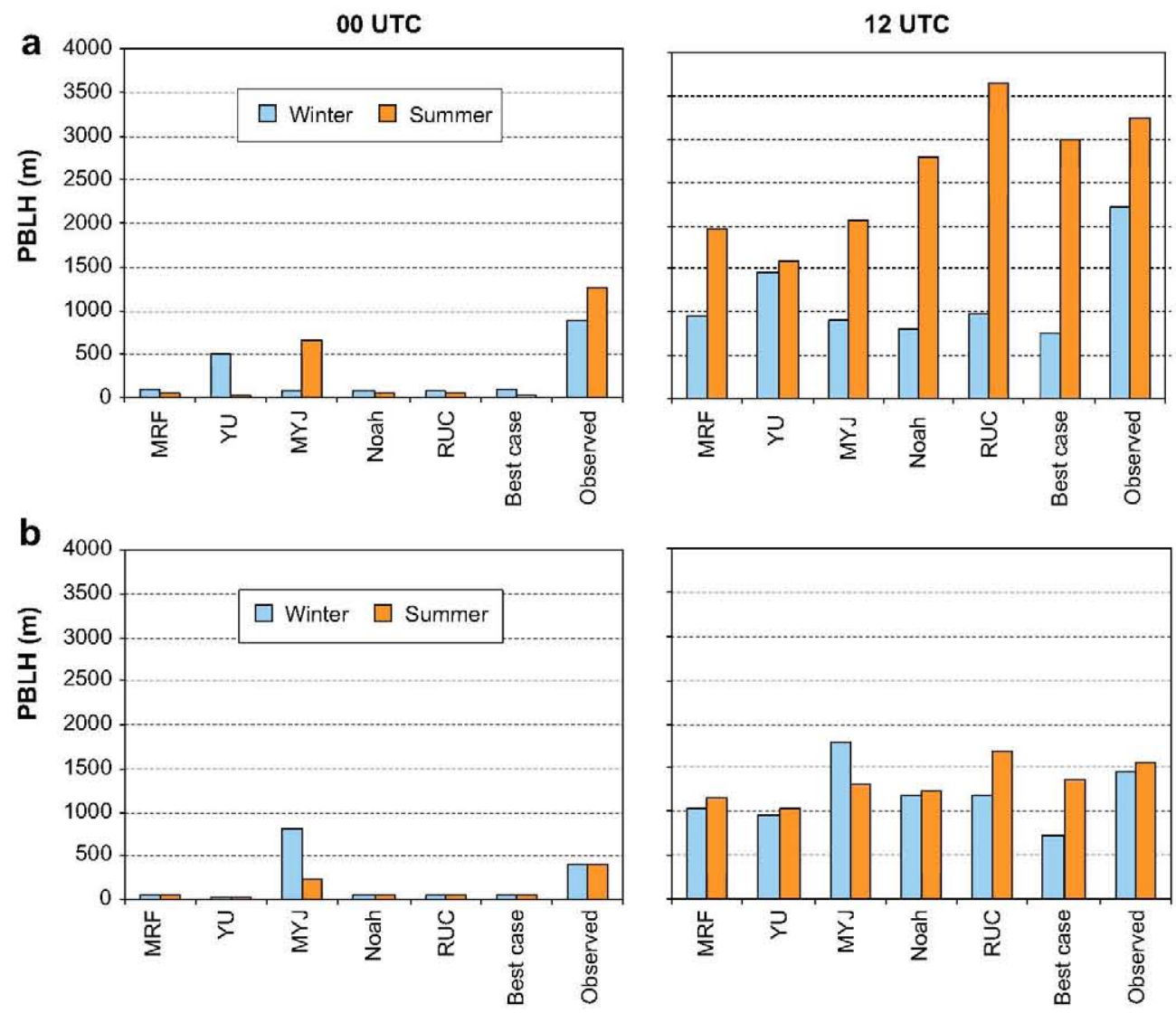

Fig. 10. PBLH comparison for Madrid (a) and Murcia (b) stations.

observations for summer. Given the uncertainty in the PBLH values estimated from the available atmospheric soundings, these results should be taken with caution.

\section{Conclusions}

Twenty-three WRF sensitivity runs were conducted over the Iberian Peninsula with a spatial resolution of $3 \mathrm{~km}$ for two one-week-long periods in winter and summer of 2005. Those numerical experiments were aimed to find the optimal setup of the meteorological model for air quality integrated assessment modelling and covered the main physic options available in the code. The main surface-level model outputs were compared with observations in the innermost domain following a specific methodology to evaluate the performance of mesoscale meteorological models for air quality purposes. Along with the statistical analysis, PBLH predictions were also assessed for a number of locations.

Rarely a particular scheme or option produced the best results for all the parameters and/or locations, so the selection was guided by the aggregated performance. The options identified as producing the best results overall were applied simultaneously in the so-called "best case". The outputs from this test confirmed that, in general, this configuration provides better performance than any other of the experiments carried out. The optimal configuration according to the sensitivity test performed is as follows:

- Physics options:

- Yonsei University (YU) Planetary Boundary Layer scheme (Hong et al., 2006)

o WRF Single-Moment 6-class (WSM6) microphysics scheme (Hong and Lim, 2006)

- Noah Land-surface model (Chen and Dudhia, 2001)

o Eta Geophysical Fluid Dynamics Laboratory (GFDL) longwave radiation scheme (Schwarzkopf and Fels, 1991)

- MM5 Shortwave radiation scheme (Dudhia, 1989)

- Other user settings:

- Time-varying Sea Surface Temperature (SST)

$\circ$ Grid + observational FDDA (nudging)

The model replicated temperature observations with a global index of agreement of 0.90. WRF also produced a rather accurate description of wind speed, especially for the EMEP stations, with a global IOA of 0.72 . Wind direction was not depicted so precisely, although it may be inferred that measurement uncertainty may be rather influential in the statistics. According to the datasets used for the evaluation, the WRF model seems to perform systematically better in Spain than in Portugal. Although the aim of the study was not to estimate model performance, the 
magnitude of the statistics indicates that the benchmarks included in the original evaluation methodology should be achieved over annual runs. According to the methodology adopted to evaluate PBLH estimations, most of the configurations, including the best case, tend to underestimate this parameter. Considering the uncertainty in the computation of observed values and that this may constitute a conservative approach for air quality modelling, these biases were considered acceptable. The effect of PBL and LSM options was explicitly evaluated in this contribution, the latter being particularly influential. Nevertheless, it was found that radiation schemes have also a clear effect in the determination of the mixing height, and therefore, should be further investigated.

This study succeeded in defining the optimal settings for the application of the WRF model over the Iberian Peninsula with a spatial resolution of $3 \mathrm{~km}$ for the two study periods. However, further work will be required to evaluate the performance of the WRF model under this configuration for annual simulations over the domain of interest. In addition, this analysis may be extended in the future to provide a more detailed insight of model performance in more homogeneous areas from the geophysical point of view, were alternative configurations may produce better results and therefore be more appropriate to drive regional air quality simulations. In such a study it would also be possible to take into account the differences in the meteorological measurement methods used in particular monitoring stations, thus increasing the significance of the analysis.

\section{References}

Akylas, E., Kotroni, V., Lagouvardos, K., 2007. Sensitivity of high-resolution operational weather forecast to choice of the planetary boundary layer scheme. Atmospheric Research 84, 49-57.

Alapaty, K., Raman, S., Mohanty, U.C., Madala, R.V., 1995. Sensitivity of monson circulations to changes in sea surface temperatures. Atmospheric Environment 29, 2139-2155.

Athanassiadis, G.A., Rao, S.T., Ku, J.-Y., Clark, R.D., 2002. Boundary layer evolution and its influence on ground-level ozone concentrations. Environmental Fluid Mechanics 2, 339-357.

Barna, M., Lamb, B., 2000. Improving ozone modeling in regions of complex terrain using observational nudging in a prognostic meteorological model. Atmospheric Environment 34, 4889-4906.

Borge, R., Lumbreras, J., Vardoulakis, S., Kassomenos, P., Rodriguez, M.E., 2007. Analysis of long-range transport influences on urban $\mathrm{PM}_{10}$ using two-stage atmospheric trajectory clusters. Atmospheric Environment 41, 4434-4450.

Borge, R., Lumbreras, J., Rodríguez, M.E., 2008. Development of a highresolution emission inventory for Spain using the SMOKE modelling system: a case study for the years 2000 and 2010. Environmental Modelling and Software 23, 1026-1044.

Byun, D.W., Ching, J.K.S., 1999. Science Algorithms of The EPA Models-3 Community Multiscale Air Quality (CMAQ) Modeling System. EPA/ 600/R-99/030, US EPA. National Exposure Research Laboratory, Research Triangle Park, NC.

Byun, D.W., Schere, K.L., 2006. Review of the governing equations, computational algorithms, and other components of the Models-3 Community Multiscale Air Quality (CMAQ) modeling system. Applied Mechanics Reviews 59, 51-77.

Carvalho, A.C., Carvalho, A., Gelpi, I., Barreiro, M., Borrego, C., Miranda, A.l., Pérez-Muñuzuri, V., 2006. Influence of topography and land use on pollutants dispersion in the Atlantic coast of Iberian Peninsula. Atmospheric Environment 40, 3969-3982.

Chen, F., Dudhia, J., 2001. Coupling an advanced land-surface/hydrology model with the Penn State/ NCAR MM5 modeling system. Part I: model description and implementation. Monthly Weather Review $129,569-585$.

Chen, S.-H., Sun, W.-Y., 2002. A one-dimensional time-dependent cloud model. Journal of the Meteorological Society of Japan 80, 99-118.

Chou, M.-D., Suarez, M.J., 1994. An efficient thermal infrared radiation parameterization for use in general circulation models. 104606. NASA Technical Memorandum 3, 85.

Collins, W.D., Hackney, J.K., Edwards, D.P., 2002. A new parameterization for infrared emission and absorption by water vapour in the National Center for Atmospheric Research Community Atmosphere Model. Journal of Geophysical Research 107, 1-20.

Dudhia, J., 1989. Numerical study of convection observed during the winter monsoon experiment using a mesoscale two-dimensional model. Journal of Atmospheric Science 46, 3077-3107.

Dudhia, J., 1996. A Multi-layer Soil Temperature Model for MM5. In: The sixth PSU/NCAR MM5 Users' Workshop, pp. 49-50. Boulder, Colorado.

Emery, C.A., Tai, E., Yarwood, G., 2001. Enhanced Meteorological Modeling and Performance Evaluation for Two Texas Ozone Episodes. Prepared for the Texas Natural Resource Conservation Commission. ENVIRON International Corporation, Novato, CA.

European Environment Agency, 2007. Air Pollution in Europe 1990-2004 EEA Report No 2/2007. ISBN: 978-92-9167-964-5. Available from: http://reports.eea.europa.eu/eea_report 2007_2/en.

Gangoiti, G., Alonso, L., Navazo, M., Albizuri, A., Perez-Landa, G., Matabuena, M., Valdenebro, V., Maruri, M., García, J.A., Millán, M., 2002. Regional transport of pollutants over the Bay of Biscay: analysis of an ozone episode under a blocking anticyclone in west-central Europe. Atmospheric Environment 36, 1349-1361.

Gardener, M.W., Dorling, S.R., 2000. Statistical surface ozone models: an improved methodology to account for non-linear behaviour. Atmospheric Environment 34, 21-34.

Gilliam, R.C., Hogrefe, C., Rao, S.T., 2006. New methods for evaluating meteorological models used in air quality applications. Atmospheric Environment 40, 5073-5086.

Grell, G.A., Dudhia, J., Stauffer, D.R., 1994. A Description of the Fifthgeneration Penn State/NCAR Mesoscale Model, NCAR Technical Note NCAR/TN-398 + STR, 122 pp.

Han, Z., Ueda, H., An, J., 2008. Evaluation and intercomparison of meteorological predictions by five MM5-PBL parameterizations in combination with three land-surface models. Atmospheric Environment 42, 233-249.

Hong, S.-Y., Pan, H.-L., 1996. Nonlocal boundary layer vertical diffusion in a Medium Range Forecast Model. Monthly Weather Review 124, 2322-2339.

Hong, S.-Y., Dudhia, J., Chen, S.-H., 2004. A revised approach to ice microphysical processes for the bulk parameterization of clouds and precipitation. Monthly Weather Review 132, 103-120.

Hong, S.-Y., Noh, Y., Dudhia, J., 2006. A new vertical diffusion package with an explicit treatment of entrainment processes. Monthly Weather Review 134, 2318-2341.

Hong, S.-Y., Lim, J.-O., 2006. The WRF Single-Moment 6-Class Microphysics Scheme (WSM6). Joumal of the Korean Meteorological Society $42,129-151$.

Janjic, Z.I., 2002. Nonsingular Implementation of the Mellor - Yamada Level 2.5 Scheme in the NCEP Mesomodel, NCEP Office Note, No. 437, $61 \mathrm{pp}$.

Kumar, S.V., Peters-Lidard, C.D., Eastman, J.L., Tao, W.-K., 2008. An integrated high-resolution hydrometeorological modeling testbed using LIS and WRF. Environmental Modelling \& Software 23, 169-181. 
Lacis, A.A., Hansen, J.E., 1974. A parameterization for the absorption of solar radiation in the earth's atmosphere. Journal of Atmospheric Science 31, 118-133.

Lee, S.-H., Kim, Y.-K., Kim, H.-S., Lee, H.-W., 2007. Influence of dense surface meteorological data assimilation on the prediction accuracy of ozone pollution in the southeastern coastal area of the Korean Peninsula. Atmospheric Environment 41, 4451-4465.

Lumbreras, J., Borge, R., Rodriguez, M.E., De Andrés, J.M., 2008. A model to calculate consistent atmospheric emission projections and its application to Spain. Atmospheric Environment 42, 5251-5266.

Mao, Q., Gautney, L.L., Cook, T.M., Jacobs, M.E., Smith, S.N., Kelsoe, J.J. 2006. Numerical experiments on MM5-CMAQ sensitivity to various PBL schemes. Atmospheric Environment 40, 3092-3110.

Miao, J.-F., Chen, D., Wyser, K., Borne, K., Lindgren, J., Svensson, M.K. Thorsson, S., Achberger, C., Almkvist, E., 2007. Evaluation of MM5 mesoscale model at local scale for air quality applications over the Swedish west coast: influence of PBL and LSM parameterizations. Meteorology and Atmospheric Physics. doi:10.1007/s00703-0070267-2.

Millán, M., Salvador, R., Mantilla, E., Artiñano, B., 1996. Meteorology and photochemical air pollution in Southern Europe: experimental results from EC research projects. Atmospheric Environment 30, 1909-1924.

Mlawer, E.J., Taubman, S.J., Brown, P.D., Iacono, M.J., Clough, S.A., 1997. Radiative transfer for inhomogeneous atmosphere: RRTM, a validated correlated $k$ model for the longwave. Journal of Geophysical Research $102,16663-16682$.

Pérez, C., Jiménez, P., Jorba, O., Sicard, M., Baldasano, J.M., 2006. Influence of the PBL scheme on high-resolution photochemical simulations in an urban coastal area over the Western Mediterranean. Atmospheric Environment 40, 5274-5297.

Pielke, R.A., Uliasz, M., 1998. Use of meteorological models as input to regional and mesoscale air quality models - limitations and strengths. Atmospheric Environment 32, 1455-1466.

Pirovano, G., Coll, I., Bedogni, M., Alessandrini, S., Costa, M.P., Gabusi, V., Lasry, F., Menut, L., Vautard, R., 2007. On the influence of meteorological input on photochemical modelling of a severe episode over a coastal area. Atmospheric Environment 41, 6445-6464.
Queen, A.N., Zhang, Y., 2008. Examining the sensitivity of MM5-CMAQ predictions to explicit microphysics schemes and horizontal grid resolutions. Part II - PM concentration and wet deposition predictions. Atmospheric Environment. doi:10.1016/j.atmosenv.2007.12.066.

Rogers, E., Black, T., Ferrier, B., Lin, Y., Parrish, D., Di Mego, G., 2001. Changes to the NCEP Meso Eta Analysis and Forecast System: increase in resolution, new cloud microphyics, modified precipitation assimilation, modified 3DVAR anslysis. In: NWS Technical Procedures Bulletin.

Russell, A., Dennis, R., 2000. NARSTO critical review of photochemical models and modelling. Atmospheric Environment 34, 2261-2282.

Schwarzkopf, M.D., Fels, S.B., 1991. The simplified exchange method revisited - an accurate, rapid method for computation of infrared cooling rates and fluxes. Journal of Geophysical Research 96, 9075-9096.

Seaman, N.L., 2000. Meteorological modeling for air-quality assessments. Atmospheric Environment 34, 2231-2259.

Sistla, G., Zhou, N., Hao, W., Ku, J.-Y., Rao, S.T., Bornstein, R., Freedman, F. Thunis, P., 2001. Effects of uncertainties in meteorological inputs on urban airshed model predictions and ozone control strategies. Atmospheric Environment 30, 2011-2025.

Skamarock, W.C., Klemp, J.B., Dudhia, J., Gill, D.O., Barker, D.M., Wang, W., Powers, J.G., 2005. A Description of the Advanced Research WRF Version 2 NCAR Tech Notes-468 + STR.

Skamarock, W.C., Klemp, J.B., 2008. A time-split non-hydrostatic atmospheric model. Journal of Computational Physics 227, 3465-3485.

Smirnova, T.G., Brown, J.M., Benjamin, S.G., Kim, D., 2000. Parameterization of cold season processes in the MAPS land-surface scheme. Journal of Geophysical Research 105, 4077-4086.

Stauffer, D.R., Seaman, N.L., 1990. Use of four-dimensional data assimilation in a limited-area mesoscale model. Part I: experiments with synoptic-scale data. Monthly Weather Review 118, 1250-1277.

Taskforce on Integrated Assessment Modelling of the UNECE Convention on Long-range Transboundary Air Pollution, 2007. Review of the Gothenburg Protocol. CIAM report 1/2007. Available from: http:// www.emep.int/publ/other/TFIAM ReviewGothenburgProtocol.pdf.

UNC Carolina Environmental Program, 2005. Sparse Matrix Operator Kernel Emissions (SMOKE) Modeling System. 